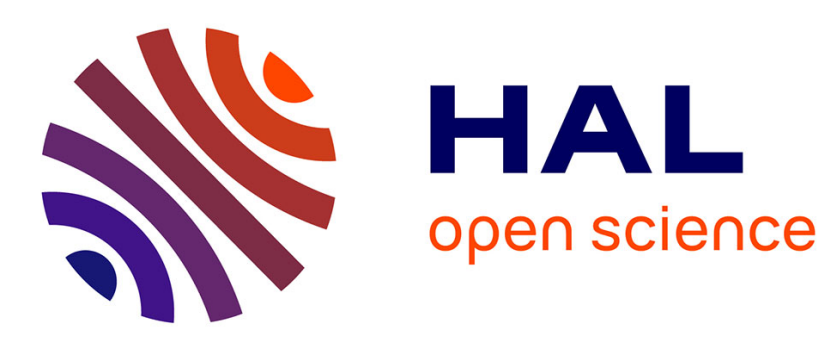

\title{
Blast actions in aircrafts: an integrated methodology for designing protection devices
}

\author{
Filippo Masi, Paolo Maria Mariano, Paolo Vannucci
}

\section{To cite this version:}

Filippo Masi, Paolo Maria Mariano, Paolo Vannucci. Blast actions in aircrafts: an integrated methodology for designing protection devices. Engineering Structures, 2018, 175, pp.895-911. 10.1016/j.engstruct.2018.08.082 . hal-01720002v2

\section{HAL Id: hal-01720002 \\ https://hal.science/hal-01720002v2}

Submitted on 23 Aug 2018

HAL is a multi-disciplinary open access archive for the deposit and dissemination of scientific research documents, whether they are published or not. The documents may come from teaching and research institutions in France or abroad, or from public or private research centers.
L'archive ouverte pluridisciplinaire HAL, est destinée au dépôt et à la diffusion de documents scientifiques de niveau recherche, publiés ou non, émanant des établissements d'enseignement et de recherche français ou étrangers, des laboratoires publics ou privés. 


\title{
Blast actions in aircrafts: an integrated methodology for designing protection devices
}

\author{
Filippo Masi \\ Laboratoire Navier - UMR8205, CNRS, ENPC \& IFSTTAR, Université Paris-Est \\ 6-8 avenue Blaise Pascal, F-77455, Marne la Vallée, France \\ e-mail: filippo.masi@enpc.fr \\ Paolo Maria Mariano \\ DICEA, Università di Firenze \\ via Santa Marta 3, I-50139 Firenze, Italy \\ e-mail: paolo.mariano@unifi.it \\ Paolo Vannucci \\ LMV, Université de Versailles et Saint-Quentin \\ 55 avenue de Paris, F-78000, Versailles, France \\ e-mail: paolo.vannucci@uvsq.it
}

\begin{abstract}
We introduce a numerical approach for evaluating the behavior of aircraft fuselages subjected to internal explosions. At variance with available approaches, we consider fluid-structure interactions through a novel integrated methodology able to take into account both stress at cruise altitude and blast fast-dynamics in interaction with pressurization not considered as a static load. The precision of the proposed numerical procedure allows us to foresee a nonstandard composite protective device.
\end{abstract}

Keywords: Continuum mechanics, blast actions, shock waves, explosions, aircrafts

\section{Introduction}

We record non-accidental airplane internal explosions since 1933, in the cargo hold of a Boeing 247D; the explosive was nitroglycerin. Table 1 shows a list of similar subsequent events. Until the explosion induced in the Boeing 707-124 in 1962, explosive devices placed in the baggage compartment plaid role. Then, in-cabin explosions became dominant. First, in 1987 liquid explosives were used and rapidly replaced by plastic explosives placed inside shoes, laptops, and other devices. Prevention based on a screening before boarding contrasted so far these actions. Gillen and Morrison [1] report a comparative study of European total expenditures on aviation security: 5.7 billion euros in 2011.

In this context, the idea of the so-called unit load devices (ULD) emerged. It is a design of luggage containers with the aim of absorbing energy from an in-cargo explosion. Examples are ULDs made of fiber-reinforced composites [2] and bilayer hardened luggage containers. In the latter case, the inner layer of lightweight foam captures debris, the outer layer mitigates pressure [3. Usual protections (see e.g. [4] and [5]) consist of blowout panels designed to be weaker than the sorrounding airframe. During an in-cabin explosion, blowout panels fail with consequent pressure decrement and possibly controlled fuselage failure. At a cruise altitude, pressurization and gravity play a non-negligible role together with the inertia of the rigid-body component of the airplane motion.

Standard experiments on the overall mechanical behavior of fuselages usually deal with a fatigue design. Those involving explosions commonly exploit an aircraft at ground, loaded just by gravity (see [6]). The experiment described in reference [7] considers a partial pressurization in a Boeing 727, while those reported 
in reference [8] refer just to a plane panel with a preceding pressurization. Large-scale effects afflict fuselage dynamics.

We record 10] attempts of designing reinforced plates made of Aluminum-based alloys or glass-reinforced Aluminum (GLARE) by taking into account blast actions. A question not yet largely investigated is, however, the behavior of the aircraft in its whole.

There are computational analyses of blast actions on fuselages, based on a Coupled-Eulerian-Lagrangian (CEL) approach. In particular A. Dacks and J. Toczyski 11 consider an explosion in the luggage compartment of an Aluminum-based fuselage, represented as a cantilever beam; their analysis neglects possible rigid-body motion of the whole structure. T. Kotzakolios and D. E. Vlachos [12] refer to Airbus A380 and introduce pressurization just as a static load on the skin.

In this paper, we propose a numerical procedure for evaluating the response of a fuselage subjected to an in-cabin explosion, with the aim of indicating a possible passive cabin protection.

At variance of other approaches, our analysis includes gravity and pressurization loads at cruising altitude. We consider different volumes of air inside and outside cabin, different velocities of traveling shock waves, and changes in pressurization.

In Section 2 we describe fuselage's geometry and schemes for the pertinent design. Sections 3 and 4 deal with the representation of blast actions and the constitutive behaviour of Aluminum-based alloys, respectively. Section 5 describes possible passive protections based on Kevlar and polyurethane foams. We describe our numerical strategy in Section 6. Finally, in Section 7 we report simulations of in-cabin explosions and analyze the reliability of the proposed passive protection.

\section{Fuselage geometry and design schemes}

Fuselage's design refers commonly to three different schemes: truss, monocoque, and semimonocoque.

- The truss design, commonly belonging to the first generation of aircrafts, consists of steel tubes, welded together in a framework.

- The monocoque scheme refers to formers, frame assemblies, and bulkheads determining fuselage's shape.

- The semimonocoque is a modification of the latter design consisting of frame assemblies, bulkheads, and formers, supplemented by additional reinforcements, called longerons, which make the structure lightweighted and stiffer. Semimonocoque fuselages are usually made of aluminium alloys, although steel and titanium are used in high temperature regions.
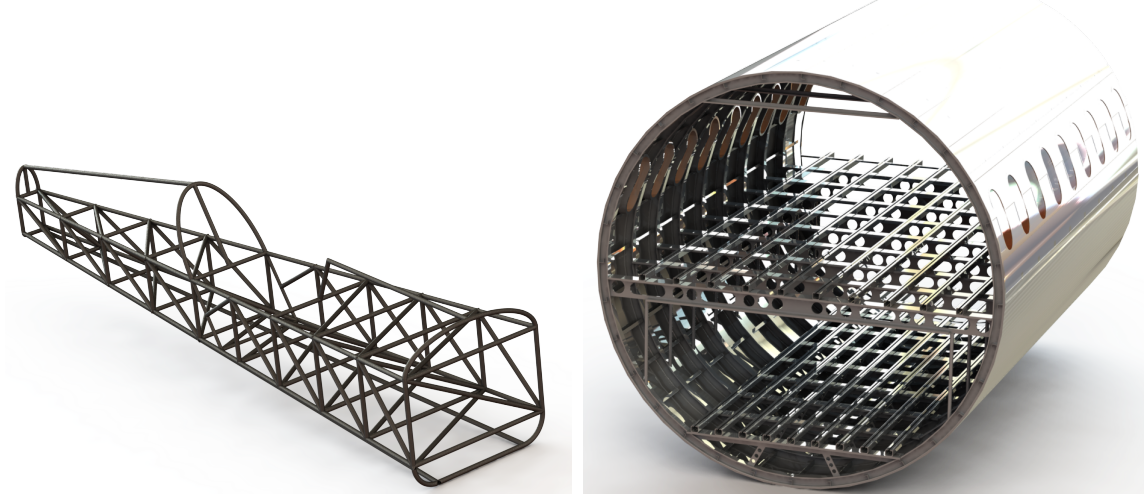

Figure 1: Truss design (left) and semimonocoque design (right). 
In the simulations presented here, we adopt the simplified semimonocoque design, shown in Figure 2 The fuselage is $4 \mathrm{~m}$ long and has a diameter of $3 \mathrm{~m}$. Longerons and bulkheads appear in Figure 2 , together with their sections.

The floor consists of plates with $8 \mathrm{~mm}$ thickness, while the skin has $2 \mathrm{~mm}$ thickness. Tied contact pairs assure continuity between different parts.

Al2024-T3 constitutes frames along the floor, longerons, and bulkheads.
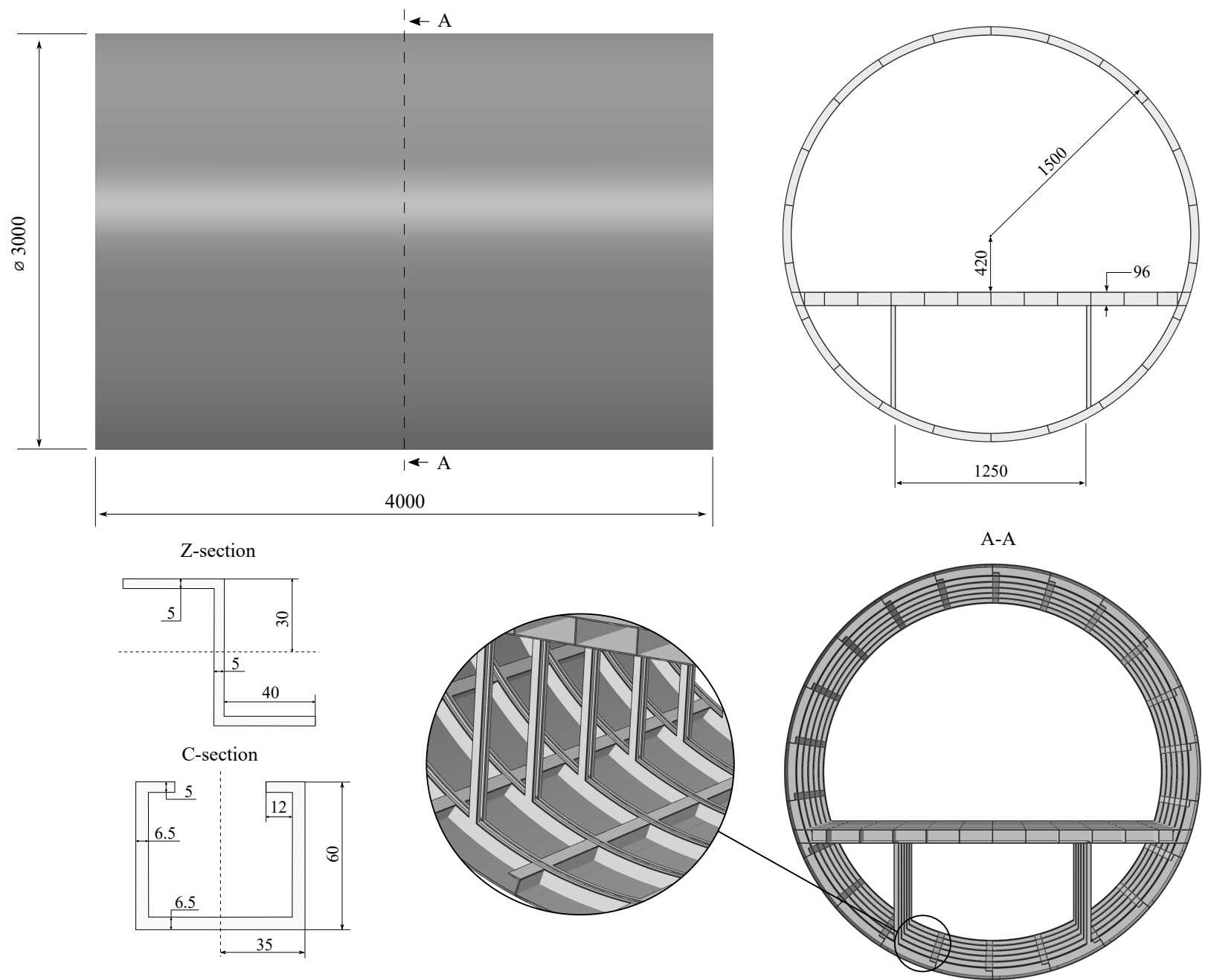

Figure 2: Fuselage, longerons and frame assemblies and related sections.

\section{Blast actions}

Explosion produces a blast wave with high-pressure accompanying high-temperature expansion of gases. First, detonation induces a supersonic shock front.

With reference to a free-field explosion, Figure 3 shows a schematic representation of the hydrostatic overpressure $P_{s}=P-P_{o}$, i.e., the difference between the hydrostatic pressure $P$ determined by the explosion and the ambient one, $P_{o}$, as a function of the stand-off distance from the explosive.

The shock front is a discontinuity surface for the velocity field. Behind the wave front, a rarefaction wave propagates. Hydrostatic pressure and density decrease to values lesser than those in the ambient before the 


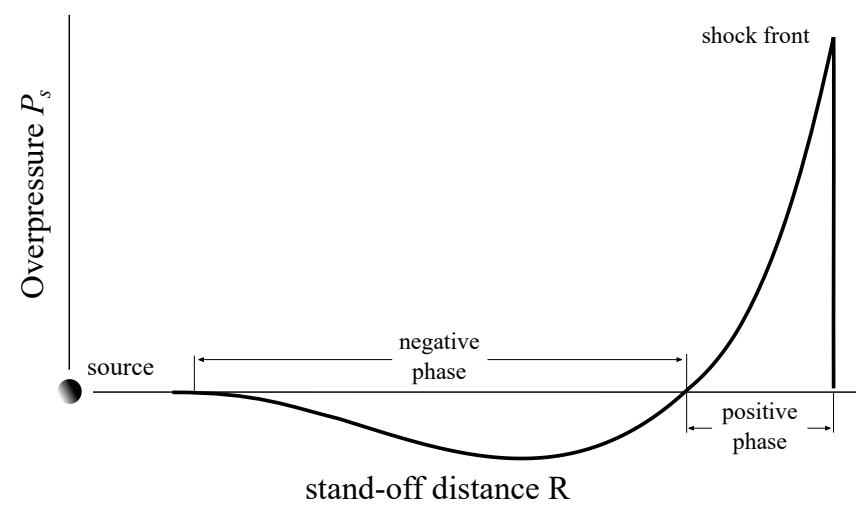

Figure 3: Spatial distribution of the overpressure.

explosion. The hydrostatic overpressure, $P_{s}$, at a point located at a distance $R$ from the explosive decreases with both time $t>t_{A}$ ( $t_{A}$ is the shock time arrival) and $R$. Generally, the time rate reduction is much greater than the spatial one. Figure 4 shows the schematic time variation of $P_{s}$ at a point. After a delay $t_{A}$ from detonation, the overpressure jumps suddenly from zero to $P_{s o}$. For $t>t_{A}$, the overpressure decreases extremely fast until the instant $t_{A}+t_{o}$, the end of the so-called positive phase. At the instant $t_{A}+t_{o}$, the so-called negative phase starts. It pertains to the rarefaction wave, triggered by the expansion of the detonation products: $P_{s}$ decreases to negative values and asymptotically approaches zero after $t_{A}+t_{o}+t_{o-}$.

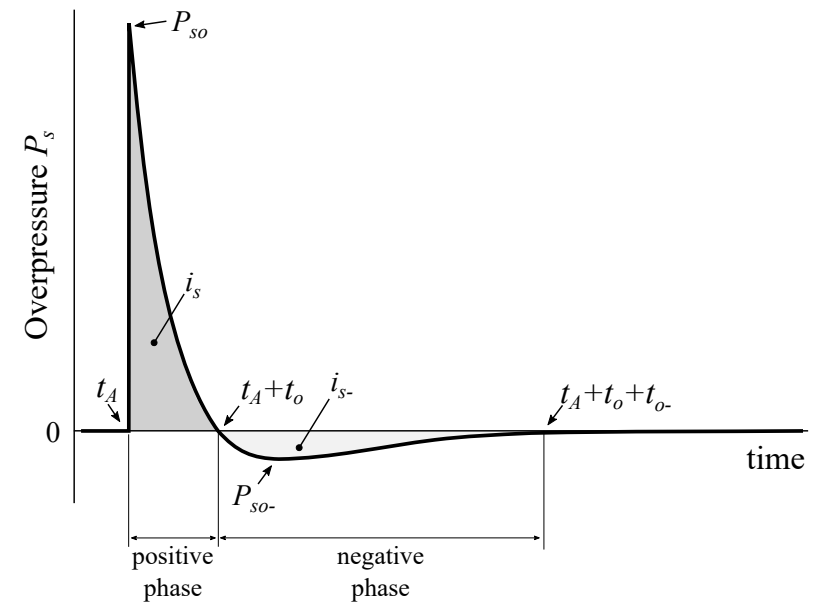

Figure 4: Scheme of the time variation of the overpressure due to a blast.

Positive and negative impulses can be defined as the integrals of the hydrostatic overpressure along positive and negative phases, respectively:

$$
i_{s}=\int_{t_{A}}^{t_{A}+t_{o}} P_{s} d t, \quad i_{s-}=\int_{t_{A}+t_{o}}^{t_{A}+t_{o}+t_{o-}} P_{s} d t .
$$

Commonly, $i_{s}$ is greater than $i_{s-}$. The duration of the negative phase is always longer than the positive one; also, $\left|P_{s o-}\right| \leq P_{s o}$. The inequality $i_{s}>>i_{s-}$ holds just in the near-field. The difference between the two impulses decays with distance.

The abrupt increase of the hydrostatic pressure within a blast wave can produce severe structural damage. When the primary shock meets a surface, it generates the so-called reflected overpressure, $P_{r}$, which is 
characterized by a time-history similar to that of the hydrostatic overpressure. Commonly, the peak $P_{\text {ro }}$ of $P_{r}$ at time $t_{A}$ is much greater than the hydrostatic overpressure $P_{s o}$ measured at the same point in the absence of any surface. The energy of a blast wave includes a contribution deriving from the hydrostatic overpressure, $P_{s}$, and another one associated to from the dynamic pressure $\hat{q}:=\frac{1}{2} \rho u|u|$, with $\rho$ the density and $u$ the velocity of gas particles. The hydrostatic overpressure is responsible for crushing of a surface. The dynamic pressure represents the amount of the kinetic energy of the stream-wise gas dynamics. It determines drag and possible lift forces. The ratio of this energy partition depends on the target geometry and its distance from the explosive charge: in the proximity of the source, $P_{s}$ and $\hat{q}$ attain almost equal values, while for increasing distances the dynamic pressure decreases until the blast wave decays to acoustic levels and the particle velocity becomes negligible. Furthermore, the drag loading induced blast wave depends on Mach and Reynolds numbers 13, 14, 15. We record different approaches to the simulation of a blast [16, 17. Here we refer to three phenomenological approaches: JWL, CONWEP, and TM5-1300. JWL stands for Jones, Wilkins, and Lee [18, 19, 20. It essentially rests on a state equation for the overpressure $P_{s}$ due to detonation:

$$
P_{s}=A\left(1-\frac{\omega \rho}{R_{1} \rho_{0}}\right) \exp \left(-R_{1} \frac{\rho_{0}}{\rho}\right)+B\left(1-\frac{\omega \rho}{R_{2} \rho_{0}}\right) \exp \left(-R_{2} \frac{\rho_{0}}{\rho}\right)+\omega \rho e_{0} .
$$

$A, B, R_{1}, R_{2}$, and $\omega$ are parameters depending upon the explosive, along with $\rho_{0}$, its density, while $\rho$ is the density of the detonation products and $e_{0}$ the internal energy per unit mass. All their values are selected to fit experimental results on a cylinder expansion test (see Table 2). Three different contributions determine $P_{s}$ : (i) the first exponential term accounts for high-pressure regime and high density of the detonation products; (ii) the second represents the intermediate pressure range; (iii) the last term is the constitutive equation of an ideal gas and defines the behaviour at low pressure or large expansion (see Fig. 5).

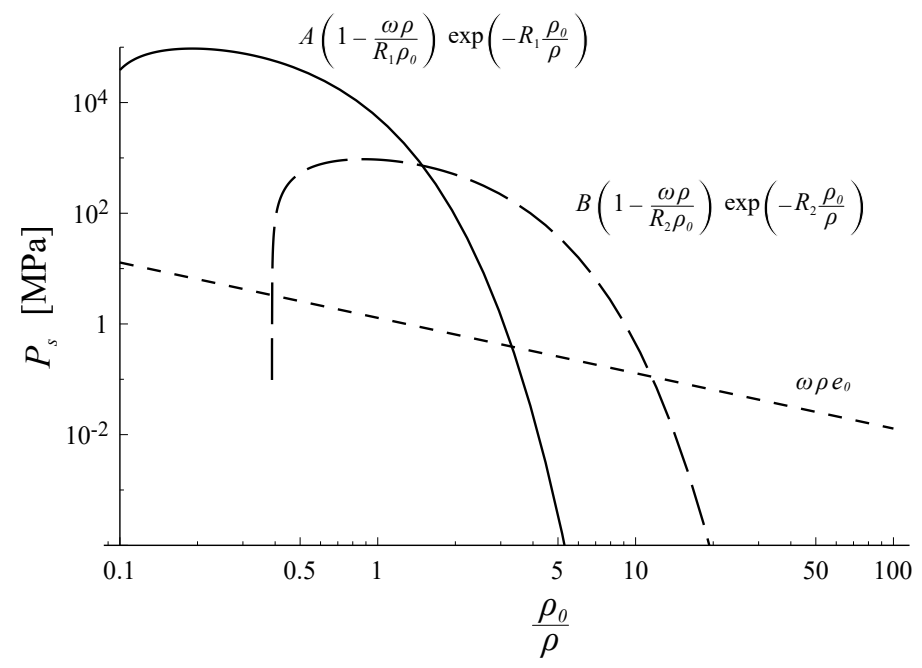

Figure 5: Overpressure inside an explosive material, 2,4,6-trinitrotoluene, at varying of the density of the detonation products.

The blast phenomenon can be modeled by taking advantage of JWL scheme through a multi-material approach, consisting of two domains: the explosive and the air, considered as an ideal gas with total pressure given by

$$
p+p_{A}=\rho \bar{R} T,
$$

where $p_{A}$ and $p$ are, respectively, ambient and current (fluid) pressures, $\bar{R}$ the product between Boltzmann's and Avogadro's constants, $T$ the current absolute temperature. At the interface between air and explosive, shock waves occur and propagate [23. When we refer to JWL and a multi-material approach to the structural design, we need a fine discretization of both charge and fluid domain; and the latter can be wide. 
Resource to empirical methods reduces computational costs. The two most commonly used empirical models rest upon related studies of the U.S. Army Corps of Engineers (USACE): the document 24] and the Technical Manual TM5-1300 [25]. They contain the model CONWEP, completed by successive documents 26]. The Joint Research Center of the European Union has produced in 2013 a technical report [27] substantially referring to these two last USACE documents and to another technicalrReport of the U.S. Army [28].

Such empirical models do not allow a detailed reconstruction of the reflected waves, with the exception of ground effects (the case of hemispherical blast). However, depending upon geometry, the concentration of the reflected waves can give rise to local effects that can be greater than the original shock wave. In the case of vaulted structures at ground, limited laterally by walls, a localized shock wave produced by the reflected waves can hit the vault with an overpressure far greater than that produced directly by the original impinging shock wave [30, [29, 32.

In the case of aircrafts, due to the cylindrical symmetry, we can have prominent effects of focalisation. Moreover, the strong thermo-fluid-mechanics coupling requires an integrated methodology able to account for both stress in the structure and fast-dynamics explosion. For all these reasons, we adopt JWL for the numerical simulations.

\section{Constitutive behaviour of some aluminum-based alloys}

Among available proposals of constitutive structures for Aluminum-based alloys, we refer here to Johnson's and Cook's [33] scheme, which includes strain hardening, strain rate and thermal softening effects. We also add the elastic component of the constitutive behaviour.

\subsection{Plastic behaviour}

Johnson-Cook's scheme is a particular type of von Mises' plasticity.

The yield stress, $\sigma^{0}$, at zero plastic strain rate, is assumed to depend on the non-dimensional temperature, $\widetilde{T}$, and the plastic component of the small strain, $\varepsilon_{\mathrm{pl}}$ :

$$
\sigma^{0}=\left[J C_{1}+J C_{2}\left(\varepsilon_{\mathrm{pl}}\right)^{n}\right]\left(1-\widetilde{T}^{m}\right)
$$

where $J C_{1}$ is the yield strength, while $J C_{2}$ and $n$ are, respectively, the hardening constant and an exponent to be determined on the basis of data fitting; $m$ is the thermal softening exponent; also

$$
\widetilde{T}=\left\{\begin{array}{cc}
0 & \text { if } T<T_{\mathrm{r}} \\
\left(T-T_{\mathrm{r}}\right) /\left(T_{\mathrm{m}}-T_{\mathrm{r}}\right) & \text { if } T_{\mathrm{r}} \leq T \leq T_{\mathrm{m}} \\
1 & \text { if } T>T_{\mathrm{m}}
\end{array}\right.
$$

where $T_{\mathrm{m}}$ and $T_{\mathrm{r}}$ are melting and reference (ambient) temperatures, respectively. For $T>T_{\mathrm{m}}, \sigma^{0}=0$ : the material melts. For nonzero plastic strain rate, $\dot{\varepsilon}_{\mathrm{pl}}$, we consider a correction to $\sigma^{0}$, indicated by $\sigma_{Y}$ and defined by

$$
\sigma_{Y}=\left[J C_{1}+J C_{2}\left(\varepsilon_{\mathrm{pl}}\right)^{n}\right]\left[1+J C_{3} \ln \left(\frac{\dot{\varepsilon}_{\mathrm{pl}}}{\dot{\varepsilon}_{0}}\right)\right]\left(1-\widetilde{T}^{m}\right)
$$

where $\dot{\varepsilon}_{0}$ is a reference strain rate, adopted for normalization purposes.

\subsection{Damage}

We associate damage to plastic strain. We define its increment, $\delta$, by

$$
\delta=\sum_{k=0}^{k=K} \frac{\Delta \varepsilon_{\mathrm{pl}, k}}{\varepsilon_{\mathrm{pl}, f}}
$$


where $\Delta \varepsilon_{\mathrm{pl}}$ is an increment of the equivalent plastic strain, $\varepsilon_{\mathrm{pl}, f}$ the plastic strain at failure, and $K$ the total number of steps in the analysis. By assumption, the strain at failure is given by

$$
\varepsilon_{\mathrm{pl}, f}=\left[d_{1}+d_{2} \exp \left(d_{3} \frac{p}{q}\right)\right]\left[1+d_{4} \ln \left(\frac{\dot{\varepsilon}_{\mathrm{pl}}}{\dot{\varepsilon}_{0}}\right)\right]\left(1+d_{5} \widetilde{T}\right),
$$

where $p$ indicates pressure, $q$ von Mises yield stress, and $d_{i}, i=1, \ldots, 5$, are failure parameters.

Tables 4 and 5 show the pertinent parameters for Al7075-T6 and Al2024-T3.

\section{Passive protections}

For their high toughness, we often make use of aramidic fibers in lightweight composites adopted in aerospace engineering. Kevlar failure emerges from a sequence of ruptures of sub-fibers. The resulting behaviour is ductile, with pertinent dissipation of energy in time. For this reason, we consider here a protection based on Kevlar fabric. We imagine a cabin load device (CLD) constructed by inserting Kevlar in the cabin, tied with longerons and bulkheads, upholstering the interiors. During an explosion, while experiencing large strain, CLD may protect the skin and prevent from fuselage perforation, as we shall see in Section 7. We can increase the protection by using foam in cavities of the fuselage such as the spaces between longerons and the interior of the floor. Foams, as energy absorbing materials, allow to mitigate the stresses due to impact, being characterised, at the same time, by low densities. Polyurethane foams are excellent candidates for blast protections.
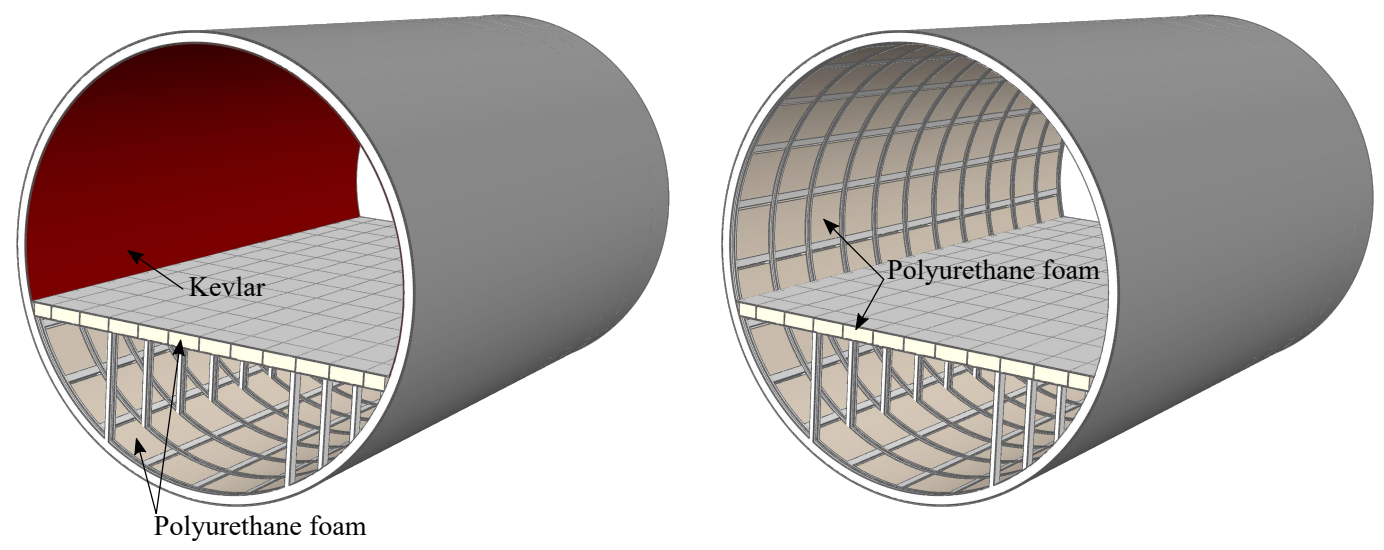

Figure 6: CLD and covering in polyurethane foam.

\subsection{Kevlar}

We assume for Kevlar fabric an orthotropic linear elastic behaviour up to failure. Also, we consider a plane stress state $\left(\sigma_{13}=\sigma_{23}=\sigma_{33}=0\right)$. With $\varepsilon$ the total elastic strain, and $\mathbb{C}$ the fourth-rank elasticity tensor, for the Cauchy stress tensor, $\sigma$, we write

$$
\sigma=\mathbb{C} \varepsilon
$$

With $E_{i}$ Young moduli, $\nu_{i j}$ Poisson ratios, and $G_{i j}$ shear moduli, $i, j=1,2,3$, in Voigt's notation, with $\gamma_{i j}=2 \epsilon_{i j}$, relation $[9]$ writes

$$
\left\{\begin{array}{l}
\varepsilon_{11} \\
\varepsilon_{22} \\
\gamma_{12}
\end{array}\right\}=\left[\begin{array}{ccc}
1 / E_{1} & -\nu_{21} / E_{2} & 0 \\
-\nu_{12} / E_{1} & 1 / E_{2} & 0 \\
0 & 0 & 1 / G_{12}
\end{array}\right]\left\{\begin{array}{l}
\sigma_{11} \\
\sigma_{22} \\
\sigma_{12}
\end{array}\right\}
$$


and

$$
\varepsilon_{33}=-\frac{\nu_{13}}{E_{1}} \sigma_{11}-\frac{\nu_{23}}{E_{2}} \sigma_{22} \neq 0
$$

The elastic parameters, collected in Table 6, refer to a woven fabric Kevlar-29 (style 735), with a polyvinylbutyral-phenolic matrix, with $18 \%$ fibers. We refer to laminated plates fabricated at a room temperature curing polyester matrix by wet lay-up techniques, with a square-weave fabric, i.e., equal number of fibers along the two orthogonal directions woven in a 2-harness satin style, where each fiber bundle loops alternately over and under two bundles in the orthogonal direction. The thickness of the fabric is approximately 0.61 $\mathrm{mm}$, with an areal density of $0.491 \mathrm{~kg} \mathrm{~m}^{-2}$. The resin matrix is a low viscosity thermosetting polyester resin (1.22 mm total thickness) [37.

We consider Hashin's failure criterion for fiber-reinforced materials [39], so we account for four different damage mechanisms: fiber tension and compression, matrix tension and compression. The initiation criterion relies on a set of damage variables, each one corresponding to a damage mechanism:

$$
\begin{gathered}
d_{f}^{t}=\left(\widehat{\frac{\sigma_{11}}{X^{t}}}\right)^{2}+\left(\frac{\widehat{\sigma_{12}}}{S^{l}}\right)^{2}, \\
d_{f}^{c}=\left(\frac{\widehat{\sigma_{11}}}{X^{c}}\right)^{2}, \\
d_{m}^{t}=\left(\frac{\widehat{\sigma_{22}}}{Y^{t}}\right)^{2}+\left(\frac{\widehat{\sigma_{12}}}{S^{l}}\right)^{2}, \\
d_{m}^{c}=\left(\frac{\widehat{\sigma_{22}}}{2 S^{t}}\right)^{2}+\left[\left(\frac{Y^{c}}{2 S^{t}}\right)^{2}-1\right] \widehat{\sigma_{22}} Y^{c}+\left(\frac{\widehat{\sigma_{12}}}{S^{l}}\right)^{2},
\end{gathered}
$$

where $X^{t}$ and $X^{c}$ are, respectively, longitudinal tensile and compressive strengths, $Y^{t}$ and $Y^{c}$ transverse tensile and compressive strengths, $S^{l}$ and $S^{t}$ in-plane and transversal shear strengths, $\widehat{\sigma_{11}}, \widehat{\sigma_{22}}$, and $\widehat{\sigma_{12}}$ the components of the effective stress tensor defined by

$$
\widehat{\sigma}=\mathrm{M} \sigma,
$$

where $\mathrm{M}$ is the damage operator, which we assume to be

$$
\mathrm{M}=\left[\begin{array}{ccc}
1 /\left(1-d_{f}\right) & 0 & 0 \\
0 & 1 /\left(1-d_{m}\right) & 0 \\
0 & 0 & 1 /\left(1-d_{s}\right)
\end{array}\right]
$$

$d_{f}, d_{m}$ and $d_{s}$ are damage variables associated with fiber, matrix and shear modes, respectively, namely

$$
\begin{gathered}
d_{f}= \begin{cases}d_{f}^{t} & \text { if } \widehat{\sigma_{11}} \geq 0 \\
d_{f}^{c} & \text { if } \widehat{\sigma_{11}}<0\end{cases} \\
d_{m}= \begin{cases}d_{m}^{t} & \text { if } \widehat{\sigma_{22}} \geq 0 \\
d_{m}^{c} & \text { if } \widehat{\sigma_{22}}<0\end{cases} \\
d_{s}=1-\left(1-d_{f}^{t}\right)\left(1-d_{f}^{c}\right)\left(1-d_{m}^{t}\right)\left(1-d_{m}^{c}\right)
\end{gathered}
$$

Table 7 collects the parameters of Hashin's failure criterion, together with the fracture energy $G_{f}$ [40, assumed to be equally distributed in longitudinal, transverse and shear directions.

\subsection{Polyurethane foam}

As usual, we consider polyurethane as a visco-elastic material with null Poisson ratio and a density of $240 \mathrm{~kg} / \mathrm{m}^{3}$. Data about the constitutive coefficients derive from uniaxial tension and compression tests, at different strain rates [41. We assume a maximal value of $3.8 \mathrm{MPa}$ for the maximum principal tensile stress. Furthermore, we consider strain rate-dependent behaviour under compression. 

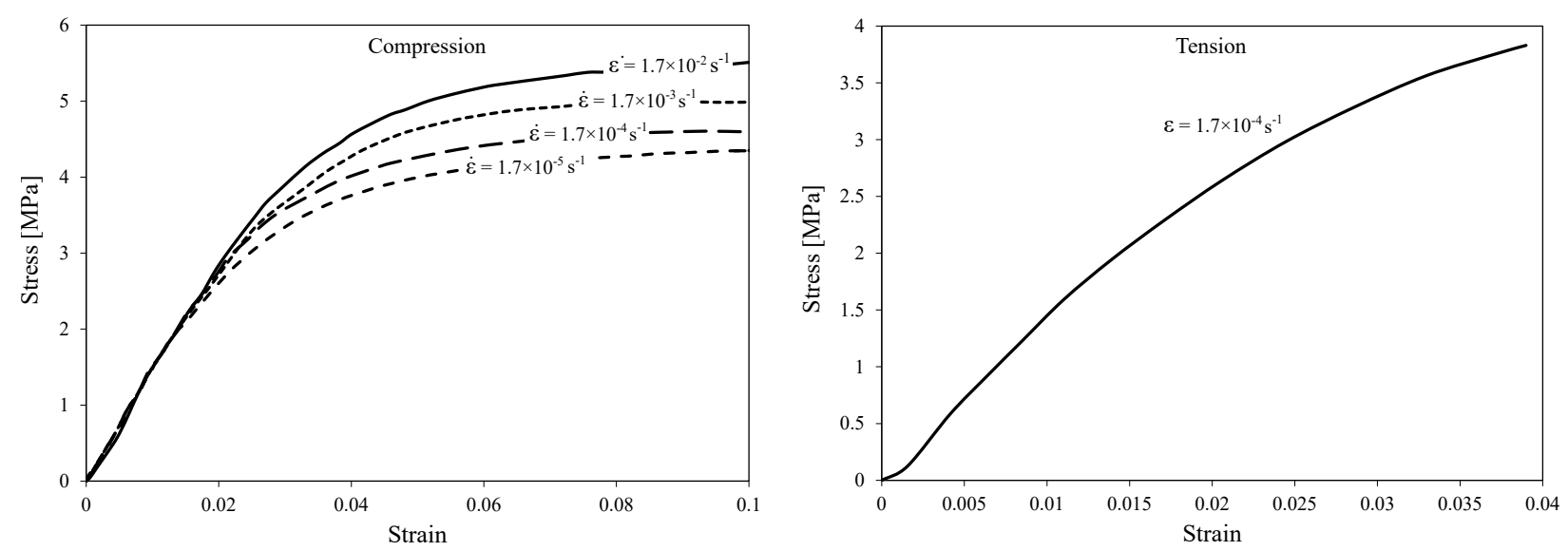

Figure 7: Behaviour of polyurethane foam in compression and tension from [41].

\section{Numerical procedure}

We simulate an in-cabin explosion by using a CEL approach: the fuselage is immersed into air; we use JWL to model the blast.

In CEL simulations, ABAQUS/Explicit takes into account the Eulerian fluid domain through the socalled volume-of-fluid-method: an additional variable within each element, the Eulerian volume fraction (EVF), describes the flow through the mesh. In our case, this approach allows us to compute not only the propagation of shock waves, but also the diffusion of the explosive inside the air domain. We describe fluid-structure interaction by using a general contact algorithm, with a null interface friction coefficient and a penalty method.

We focus our attention just on a portion of the fuselage. For the sake of simplicity, we do not include seats, passengers, and baggage, so that we do not consider the projectile-like behaviour of fragments of bodies invested by an explosion. We do not account for bolts, rivets, and points of adhesive bonding, which are possible source of stress concentration, influencing the damage pattern. This is a limitation of our numerical analyses. However, our aim is to present a procedure, showing its potentialities, rather than designing a specific aircraft.

For the structure under analysis, we account for the stress state at cruising altitude, before explosion. Our methodology consists of two steps:

- First, we develop a quasi-static analysis by applying increments of gravity and a distributed load equivalent to lift, on the lower half of the fuselage. Figure 8 shows boundary conditions, which allow a rigid body motion as soon as vertical loads become unbalanced.

- The results are the initial state of a subsequent simulation in which we include pressurization by means of a pressure gradient between internal and external volumes of air. We consider the aircraft to be at $10000 \mathrm{~m}$ altitude, while the equivalent effective cabin is at $2000 \mathrm{~m}$.

Figure 9 is a pertinent scheme.

We use the stress state obtained from the second analysis as initial state of the simulations of an internal explosion at cruising altitude.

To account for blast heat release, we adopt a Coupled-Temperature-Displacement (CTD) analysis. The equilibrium state achieved at the end of the second step is the initial state of a CEL-CTD explicit analysis of blast waves on the structure. Table 2 collects constitutive parameters for explosive and air. 

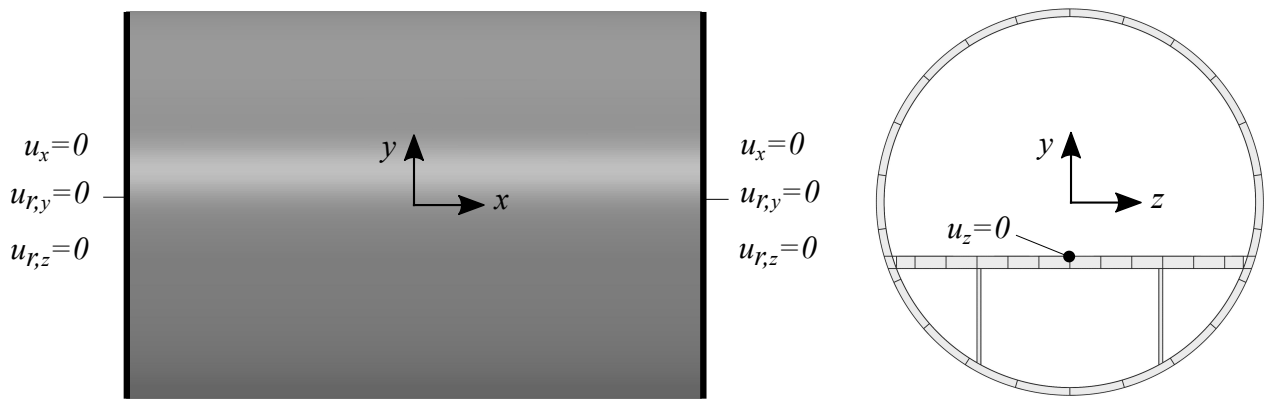

Figure 8: Symmetric boundary conditions (left) along z axis applied in every analysis and no $\mathrm{x}$-translation boundary condition (right) applied in the CEL-CTD analysis.

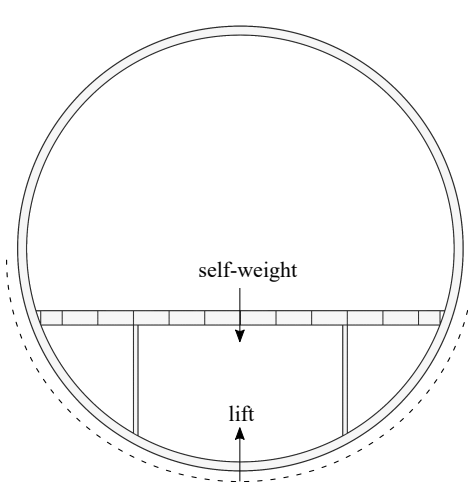

structural quasi-static analysis

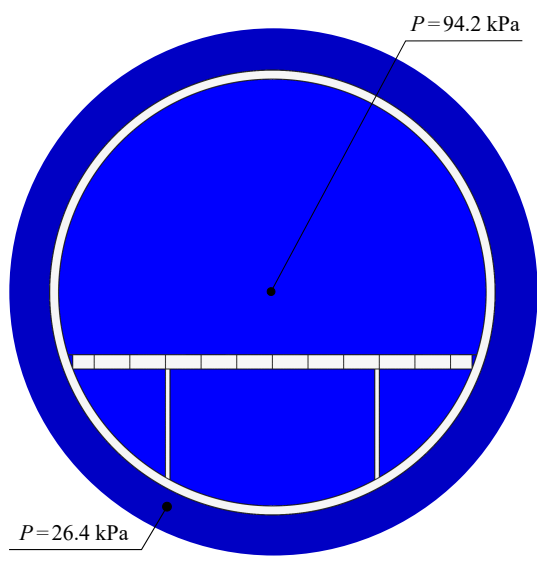

CEL approach quasi-static analysis

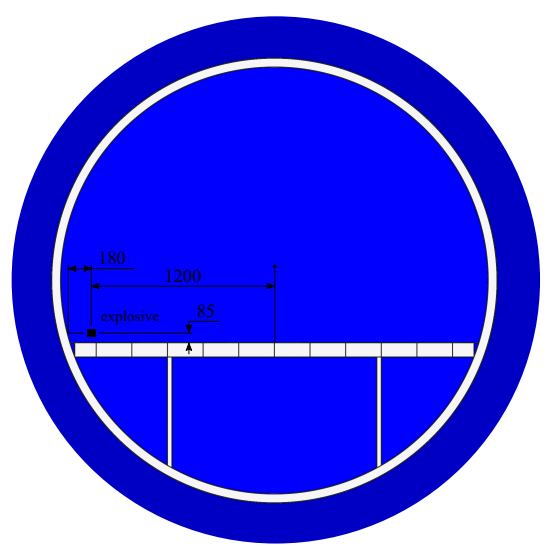

CEL approach

CTD explicit analysis

Figure 9: Schematic representation of the procedure proposed for evaluating the stress state of the structure.

\subsection{Mesh sensitivity of the fluid domain}

The air domain is shown in Figures 10 and 11. It is decomposed into $1.156 \times 10^{6} 8$-nodes hexaedral volume elements, for $5.78 \times 10^{6}$ degrees of freedom (DOF).

Boundary conditions consist on non-reflecting outflow, applied to the whole boundary.

We subdivide the air domain into two different volumes: inside and outside the fuselage. In the latter case, the domain corresponds to a cylinder with a diameter of $4 \mathrm{~m}$.

The choice of the mesh fineness derives from a convergence analysis. We have considered six different meshes for the air domain: from the coarsest, $\mathrm{M}_{1}$, with $0.58 \times 10^{6} \mathrm{DOF}$, to the finest, $\mathrm{M}_{6}$, with $10.54 \times 10^{6}$ DOF. For each mesh, we have computed the blast overpressure due to an explosive charge placed in the middle of the fuselage length, identified by plane 1. Figure 10 indicates charge and gauge points (further details are in Figure 11.

Figure 12 shows the relative error evaluated for meshes $M_{1}, \ldots, M_{5}$ with respect to mesh $M_{6}$, and defined by

$$
e r r=100\left|\frac{p_{M_{i}}-p_{M_{6}}}{p_{M_{6}}}\right|,
$$

where $p_{M_{i}}$ is the peak overpressure in the gauge point evaluated for grid $\mathrm{M}_{i}$, while $p_{M_{6}}$ the corresponding value in the reference mesh $\mathrm{M}_{6}$. In showing results, we refer to the mesh $\mathrm{M}_{5}$, with $5.72 \times 10^{6}$ DOF. Figure 12 
shows also a comparison between the overpressure obtained by using JWL and the analogous result emerging from an empirical model based on Kingery's and Bulmash's relations, complemented by Frielander's equation 42]. In such a scheme, $Z \frac{R p_{0}^{1 / 3}}{\rho e_{0}}$ plays a role. $R$ is the geometric distance from the explosive, $p_{0}$ the ambient pressure, $\rho$ the density, $e_{0}$ already introduced in relation 2 42. Moreover, we have considered the impulse reduction due to the angle of incidence of the wave over the structure.

By comparing the two analyses, we record for JWL a lower pressure peak, a clearing-type effect, and an almost negligible negative phase. We do not consider confined explosions, because the fuselage may be perforated, reducing the confinement (see also the remarks in Appendix).

\subsection{Mesh sensitivity of the structural domain}

For the fuselage we have considered four-nodes thermally coupled shell elements, supported by the explicit solver of ABAQUS. A numerical convergence analysis corroborates the choice. As already pointed out, first we consider gravity and lift loads. Then, the equilibrium state enters a second analysis in which we consider the fluid domain, discretized with the selected mesh $\mathrm{M}_{5}$, and we apply the pressurization load.

The convergence analysis rests on explicit schemes for nine different structural meshes $\mathrm{MS}_{i}, i=1, \ldots, 9$, with characteristics in Table 8

We have evaluated convergence as for the air domain, computing for each mesh $\mathrm{MS}_{i}$, with $i=1, \ldots, 8$, the errors $\Delta \varepsilon$ pertaining to the evaluation of the strain $\varepsilon$, relatively to a reference $\varepsilon^{r}$, calculated for the finest mesh, $\mathrm{MS}_{9}$. We define

$$
\Delta \varepsilon=\left|\frac{\varepsilon-\varepsilon^{r}}{\varepsilon^{r}}\right|,
$$

for any mesh $\mathrm{MS}_{i}$. The strain refers to the point indicated in Figure13. The same figure shows the result. Consequently, we have selected the mesh $\mathrm{MS}_{8}$ for the final simulations. A detail of the structural mesh $\mathrm{MS}_{8}$ appears in Figure 14.

The explosive has an initial square shape and has been discretized by using elements of $3 \mathrm{~mm}$.

We use parallel computing for decreasing significantly computational time. All the simulations exploited a 24-core workstation. 

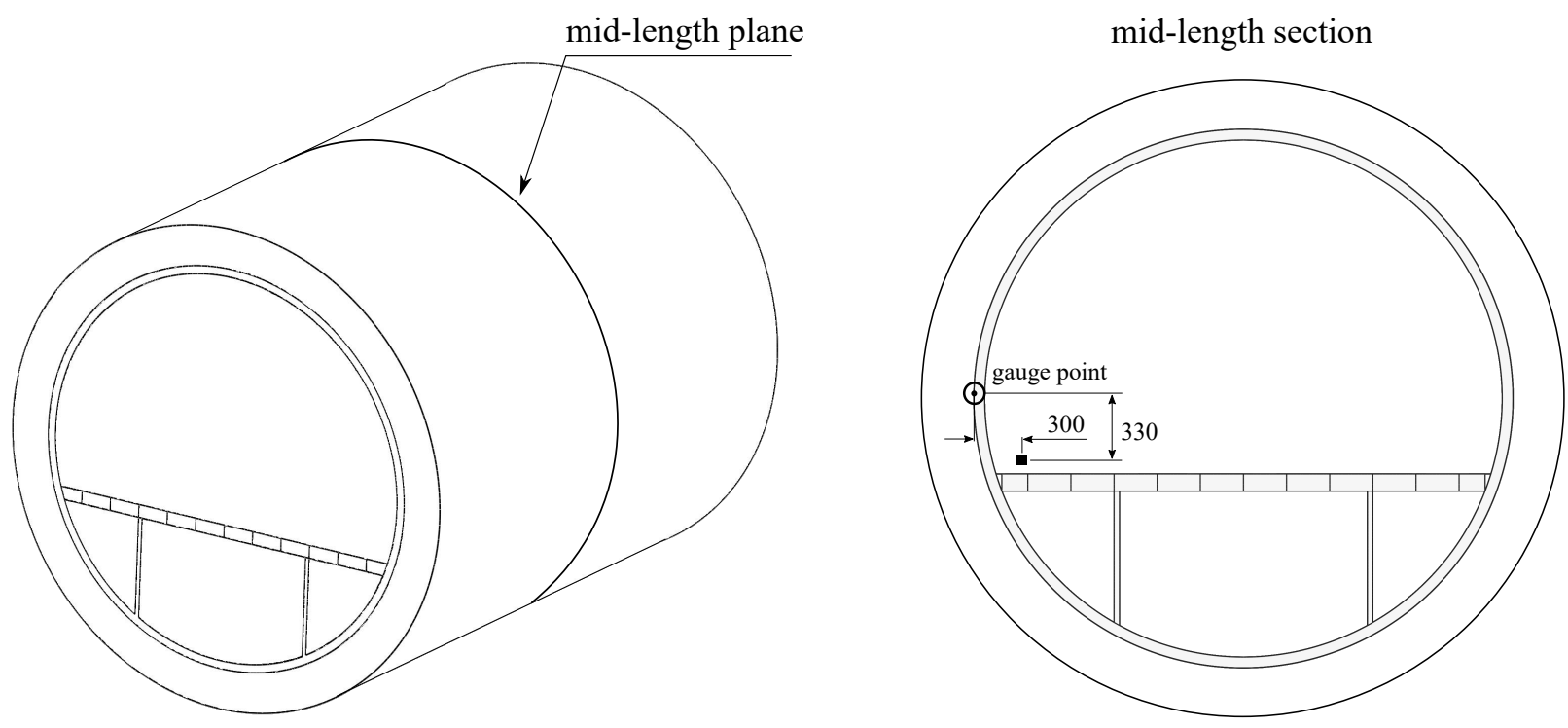

Figure 10: The air domain: overall view (left), and location of the gauge and source points (right).

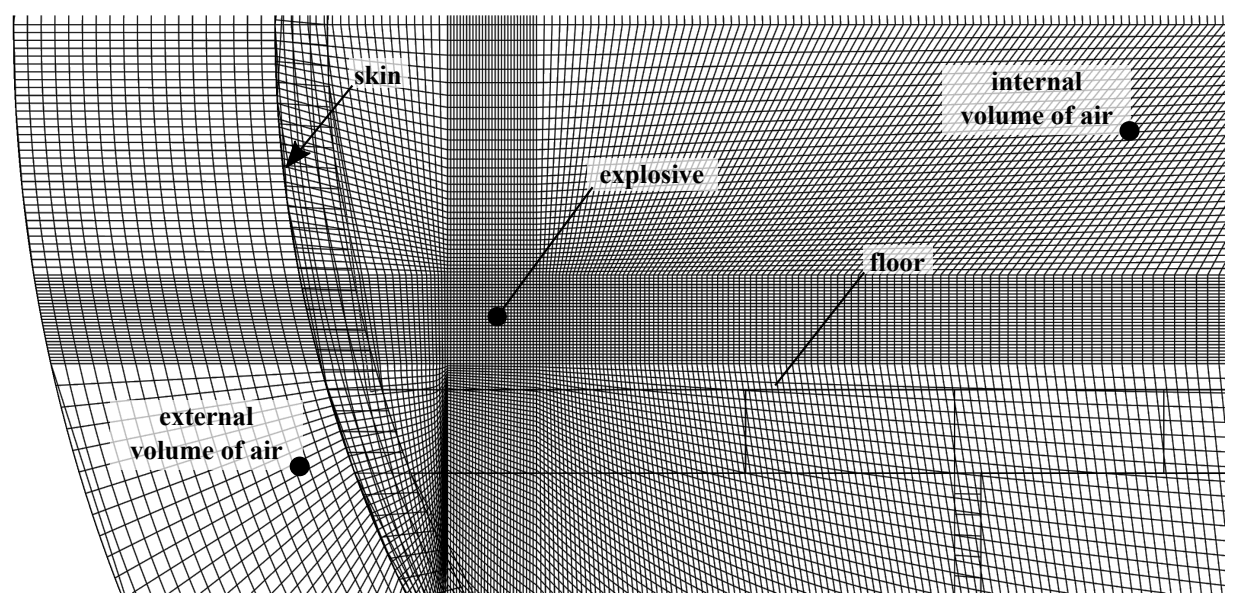

Figure 11: Detail of mesh $\mathrm{M}_{5}$ and discretization of the explosive.
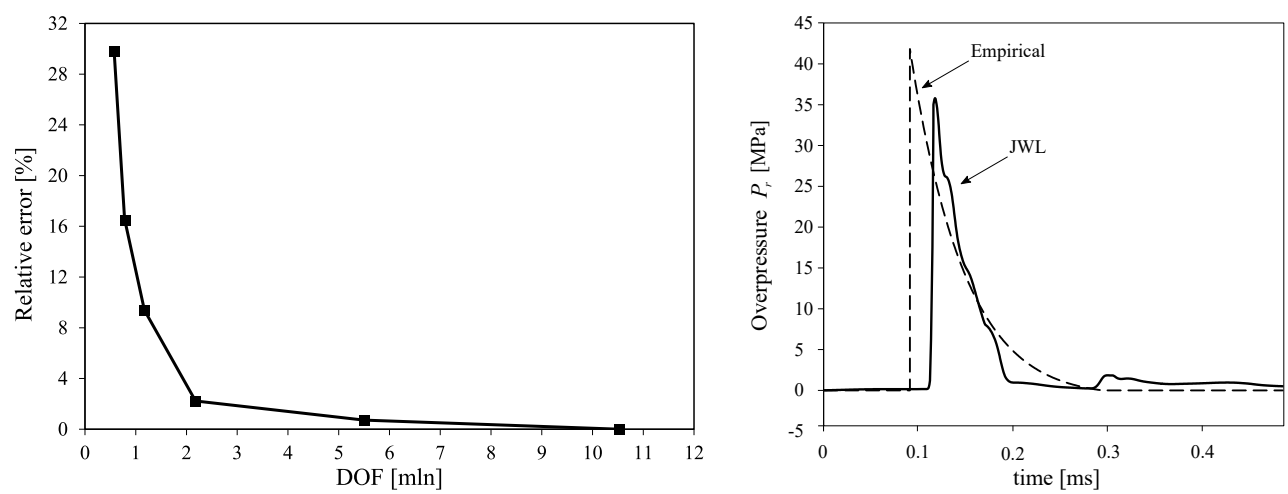

Figure 12: Relative error, eq. 21, for the gauge point as function of the number of DOF (left). Comparison of the overpressure time history at the gauge point between the numerical simulation with mesh $M_{5}$ and empirical model based on the relationships of Kingery-Bulmash (right). 

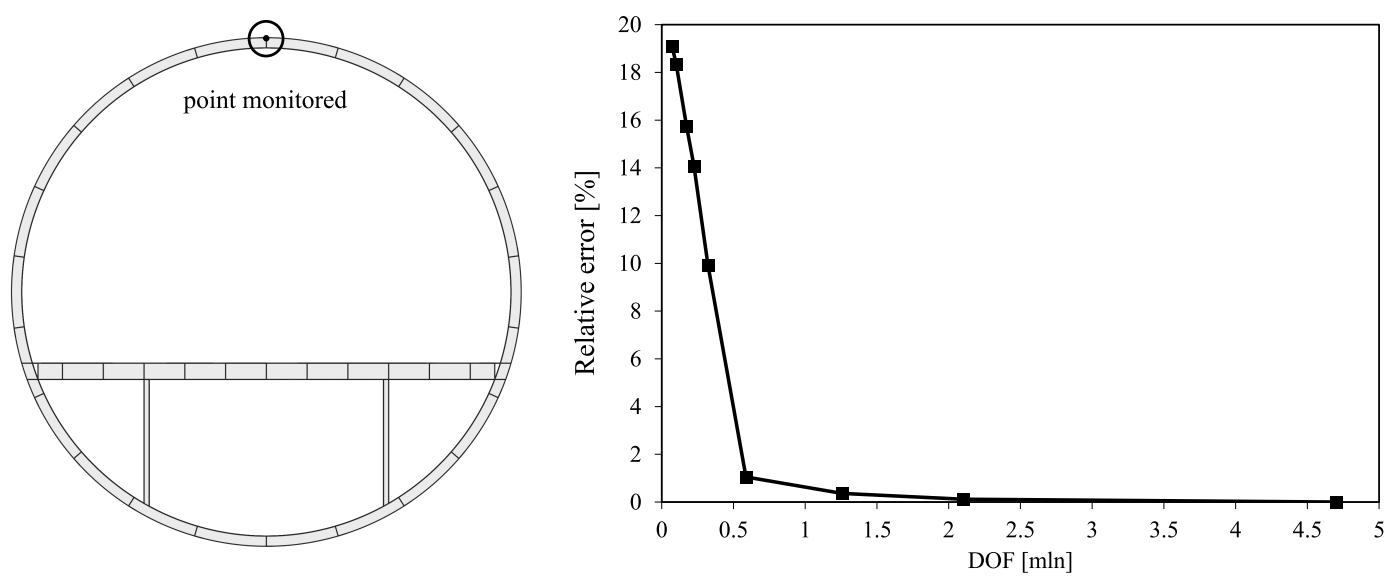

Figure 13: Relative error $\Delta \varepsilon$ versus DOF, with respect to a point of the skin.

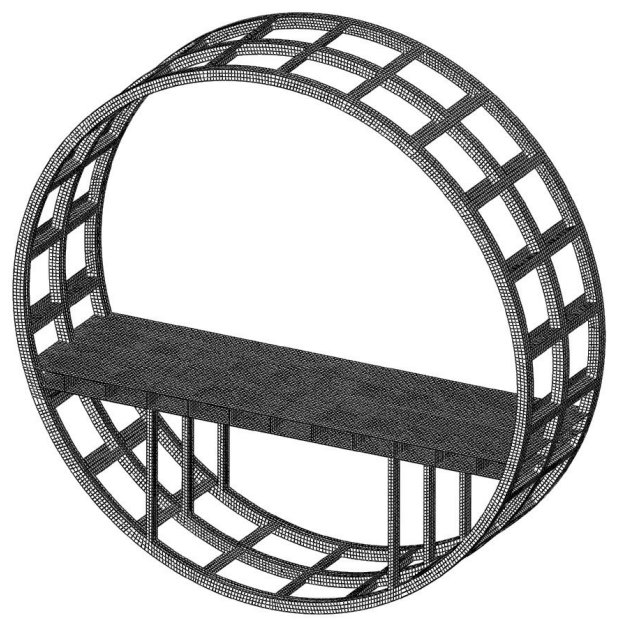

Figure 14: Detail of the structural mesh $\mathrm{MS}_{8}$. 


\section{Numerical results}

First, we have simulated a blast, produced by an in-cabin explosion of $0.5 \mathrm{~kg}$ TNT equivalent, by using a CEL-CTD analysis. Then, we have designed a CLD (Fig. 6) by suing the results. The stable time step of the explicit schemes, mostly afflicted by the small elements size (see [36]), varies from $2.9 \times 10^{-7} \mathrm{~s}$ to $5.7 \times 10^{-11} \mathrm{~s}$. Therefore, the computational time required for running a short time period (3.5 milliseconds) analysis is about 35 hours.

\subsection{In-cabin explosion simulations}

Figures 15, 16 and 17 report the results. The evolution of the pressure field thorugh the air domain is in Figure 15 .

The blast is really fast and so is fuselage's reaction, which can be evaluated already in the first 3 milliseconds. The final structural damage is in Figure 16. while the progressive response of bulkheads, longerons and skin to the blast is in Figure 17. We do not consider cutouts along which longerons can run. The results confirm that a small amount of charge, capable just of piercing the skin at sufficiently high altitude, can be the origin of a disaster. The principal shock front produces a hole in the skin enlarged by the subsequent decompression until global failure. The overpressure destroying the skin around the charge may break also the floor (see Fig. 15). In this way it determines a secondary shock, which propagates inside the cargo hold and opens another hole in the bottom half of the skin.

Figures 18,19 , and 20 refer to the analogous analysis developed foreseeing the sole Klevar-based protection.

If we use just Kevlar, in protecting the fuselage, we have an increment in weight of about 1.2 per cent, while the presence of foam increase weight up to 38 per cent.

\subsection{Assessing the reliability of the protective $C L D$}

Figure 22 shows the evolution of the pressure field in the air domain considering the protective CLD: we get mitigation of blast waves, thanks to both materials and the way the protections are inserted. By comparing Figures 22 and 15, we can see the advantages of using a Kevlar fabric as a result of the smooth evolution of the principal shock front and reflected waves with a lower magnitude. Indeed, such a fabric behaves like a second skin, much less stiff and tougher than the one made of Al7075-T6. Its main effect is a reduction of the magnitude of reflected blast waves.

Figures 23 and 24 show the structural damage and the progressive response of fuselage and CLD, respectively. Skin can withstand an internal explosion of $0.5 \mathrm{~kg}$, being not punctured, and floor is only partially damaged, avoiding the failure of the bottom half skin, due to venting, as shown in Figure 22, where any blast wave penetrates inside the cargo hold.

Figure 25 displays the time-evolution of the energy dissipated along the damage process in the three cases here studied: a) without protections, b) with Kevlar, and c) with the protective CLD. A Kevlar-based protection (case b) results in a reduction of the amount of structural damage equal to $\sim 79 \%$ with respect to case a. The protective CLD reduces further the zone of the fuselage affected by damage by $\sim 46 \%$ of the one computed without protections.

We remark that in performing our analyses by assuming just static pressure load, we do not record damage. The circumstance underlines the difference between our approach and those based on static pressure load.

\subsection{Further remarks}

Numerical simulations dealing with the behaviour of fuselages under blasts are usually based on the application of pressurization load as a distributed action on the skin independently of the pressures of the surrounding volumes of air. We investigate this assumption in Appendix. 
The simulations presented here allow us to capture the fast-dynamics due to an internal explosion. The difference between numerical results and reality requires reliable experimental tests. However, our results furnish indication addressing towards a reasonably profitable design.

We have used just a portion of a fuselage free of cabin furnitures, passengers, and baggage. Also, in our analyses we did not include after-burning, conduction, and chemical effects. These choices and those already mentioned are limitations of our work. However, our aim is just to indicate a nonstandard methodology of analysis, showing its potentialities, rather than designing a specific airplane.

We record (ground) tests on Kevlar-reinforced cabins as a blast mitigation measure [43, [4]. Our analyses at a cruising altitude corroborate that choice. However, the methodology that we propose can be used to analyze other possible mitigation measures. 

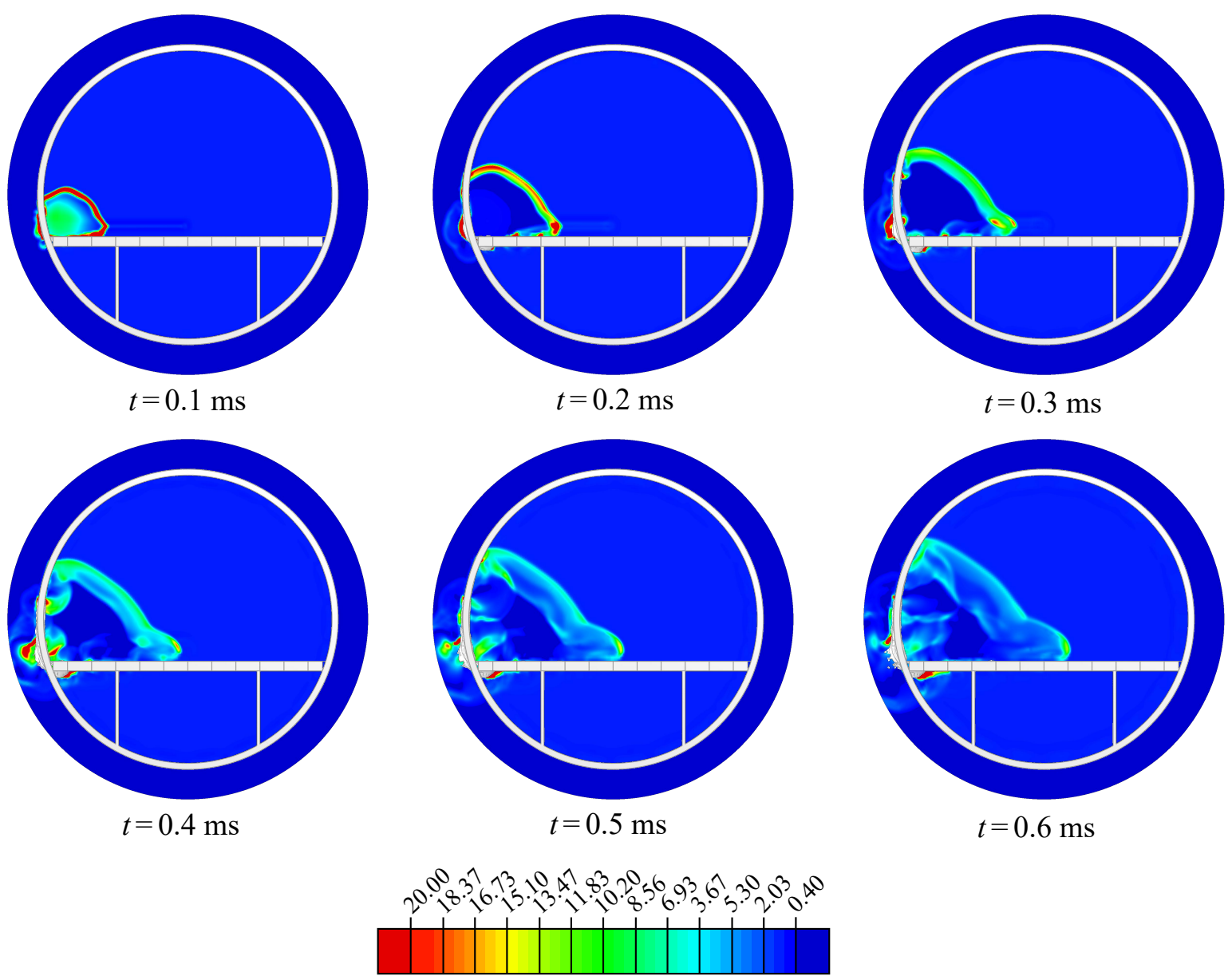

Pressure [MPa]

Figure 15: The evolution of the pressure field through the air domain.
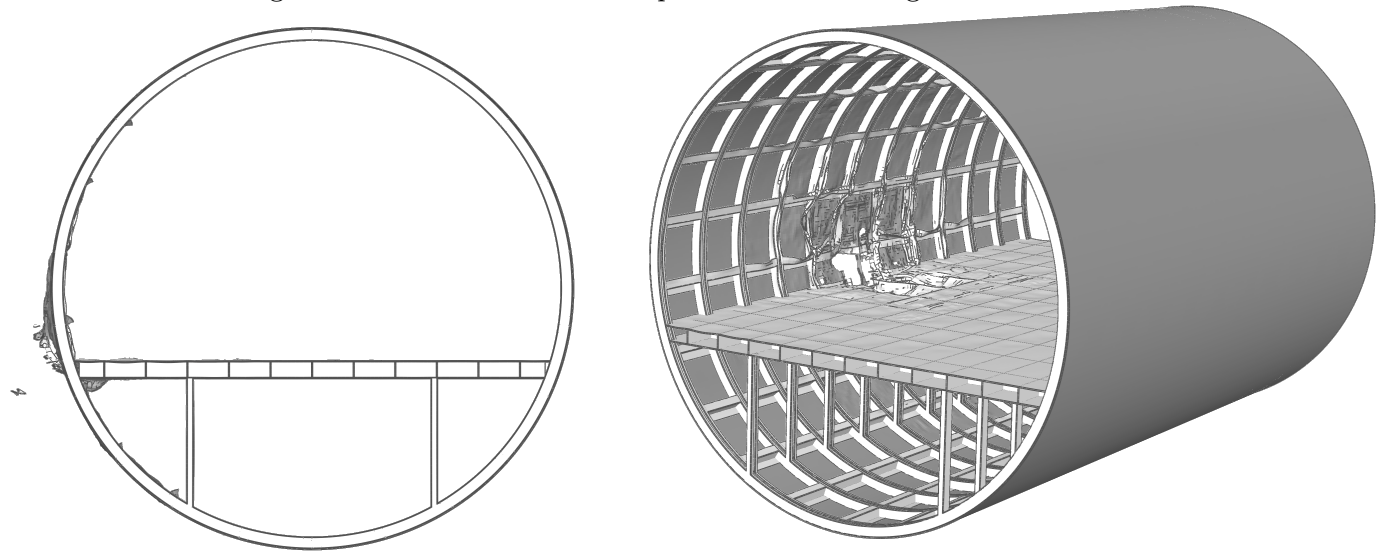

Figure 16: Structural damage at the end of the calculations. 

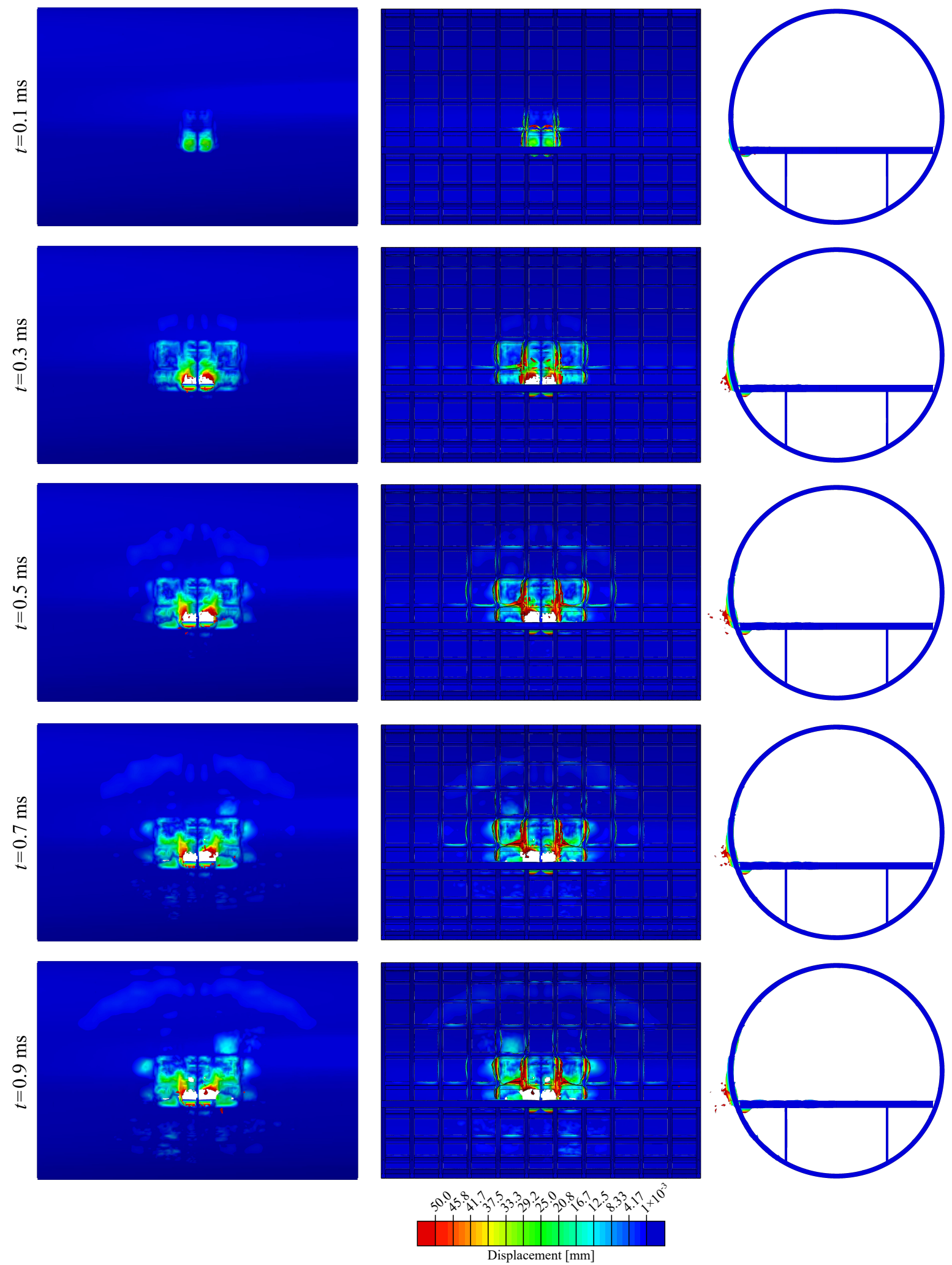

Figure 17: Simulation of an internal blast: external (left), internal (center), and front views (right). 


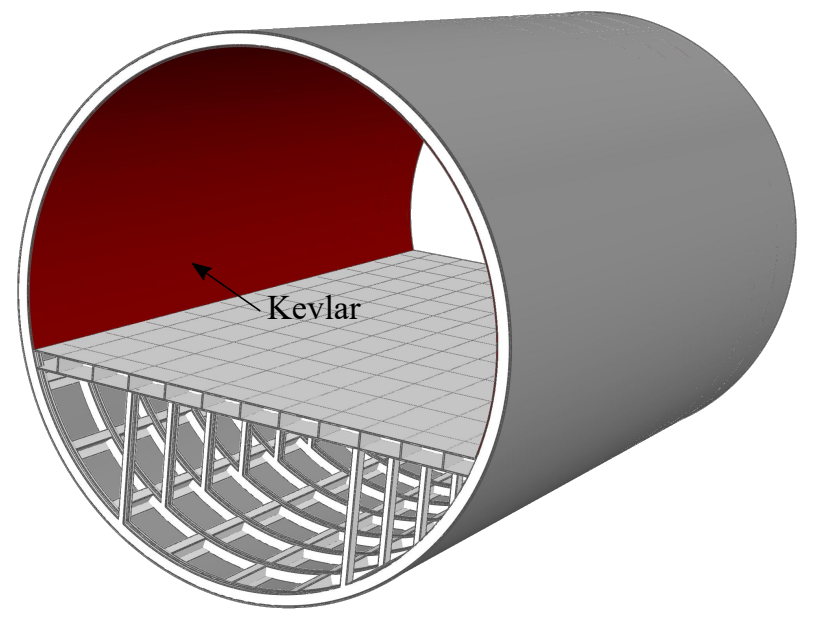

Figure 18: Liner in Kevlar. 

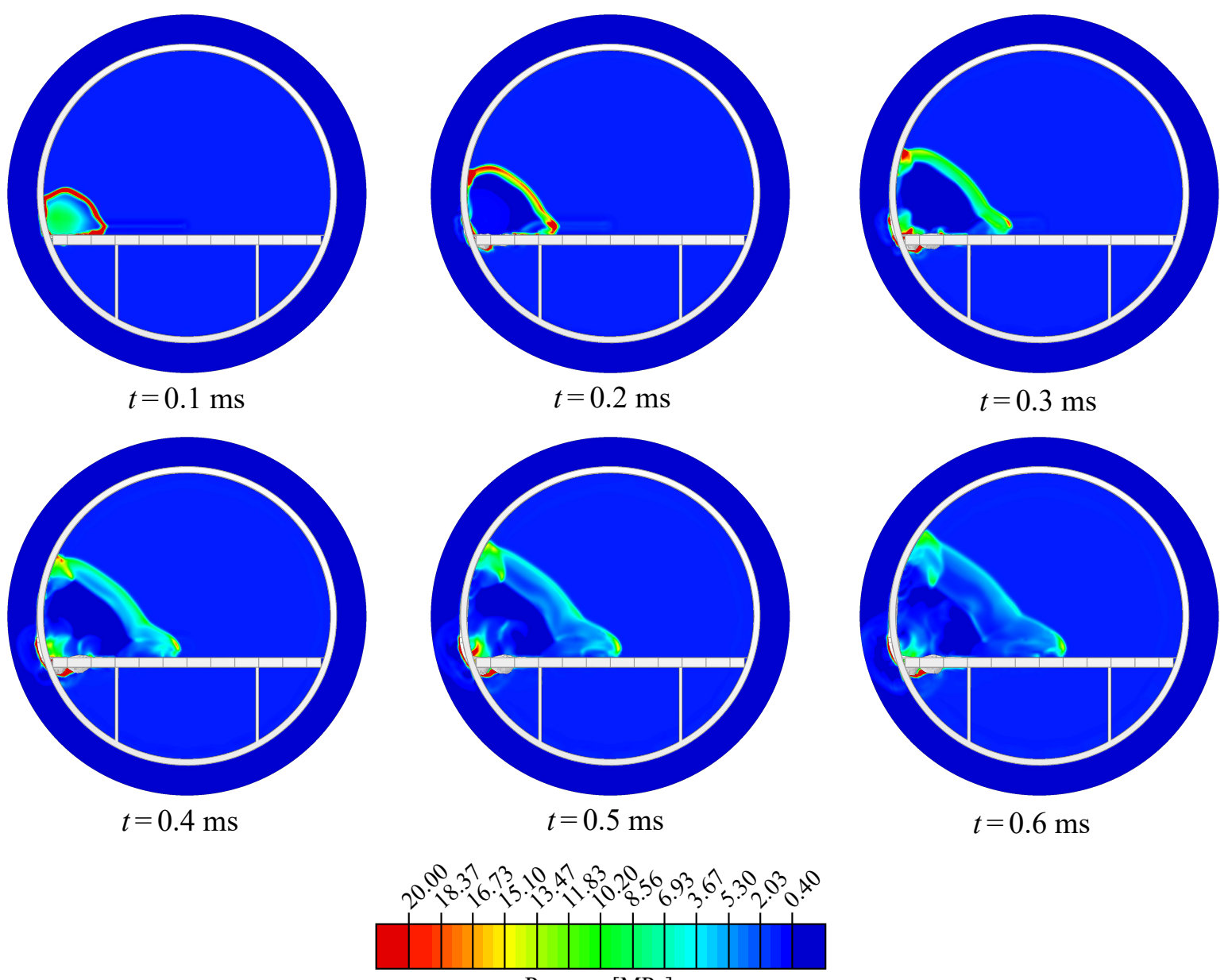

Pressure $[\mathrm{MPa}]$

Figure 19: The evolution of the pressure field through the air domain, with the liner in Kevlar.
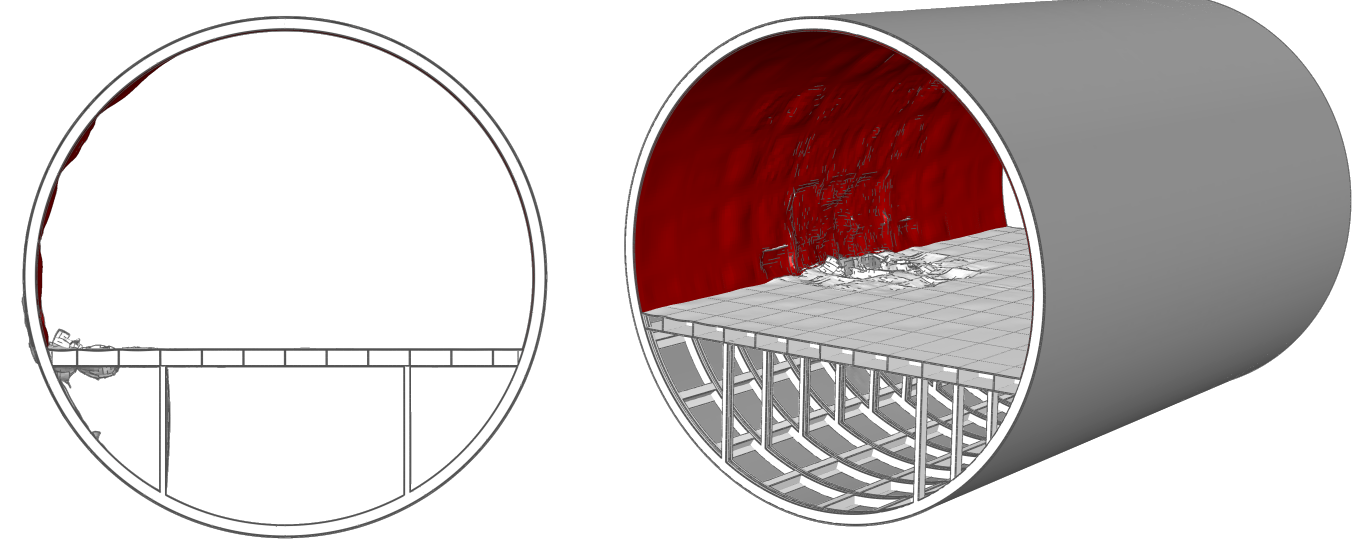

Figure 20: Structural damage at the end of the calculations, with the liner in Kevlar. 

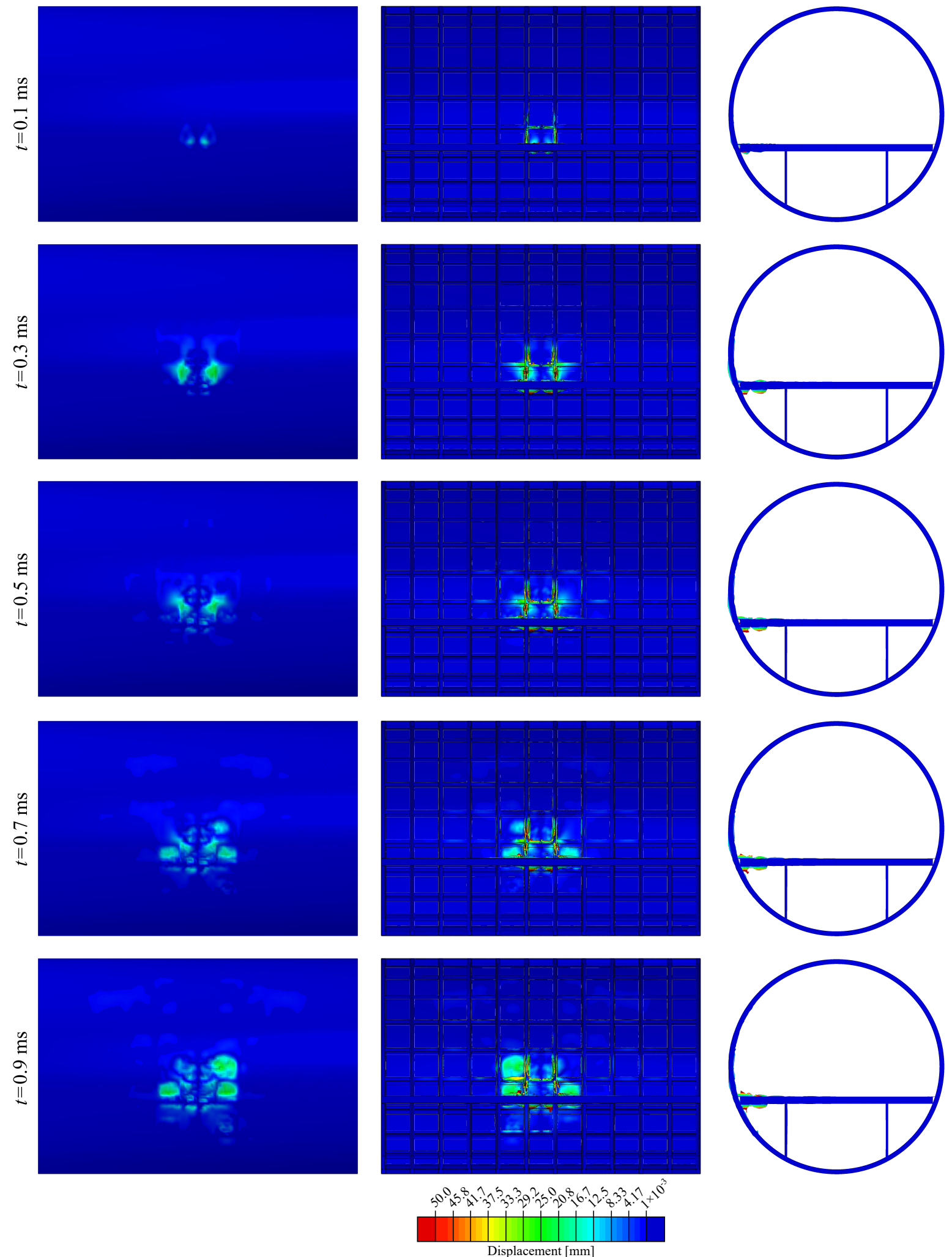

Figure 21: Simulation of an internal blast with the liner in Kevlar: external (left), internal (center), and front views (right). 

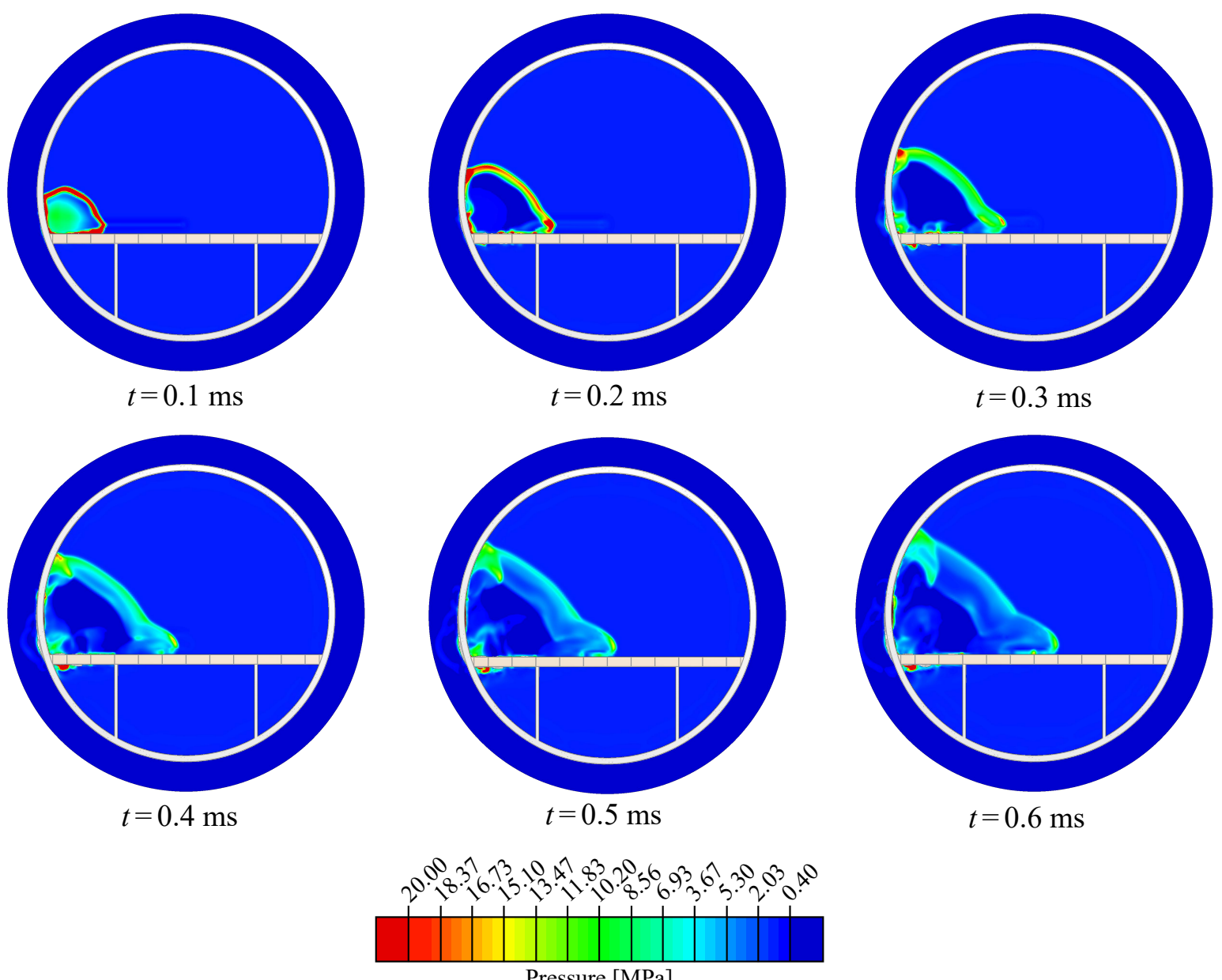

Pressure [MPa]

Figure 22: The evolution of the pressure field through the air domain, with CLD.
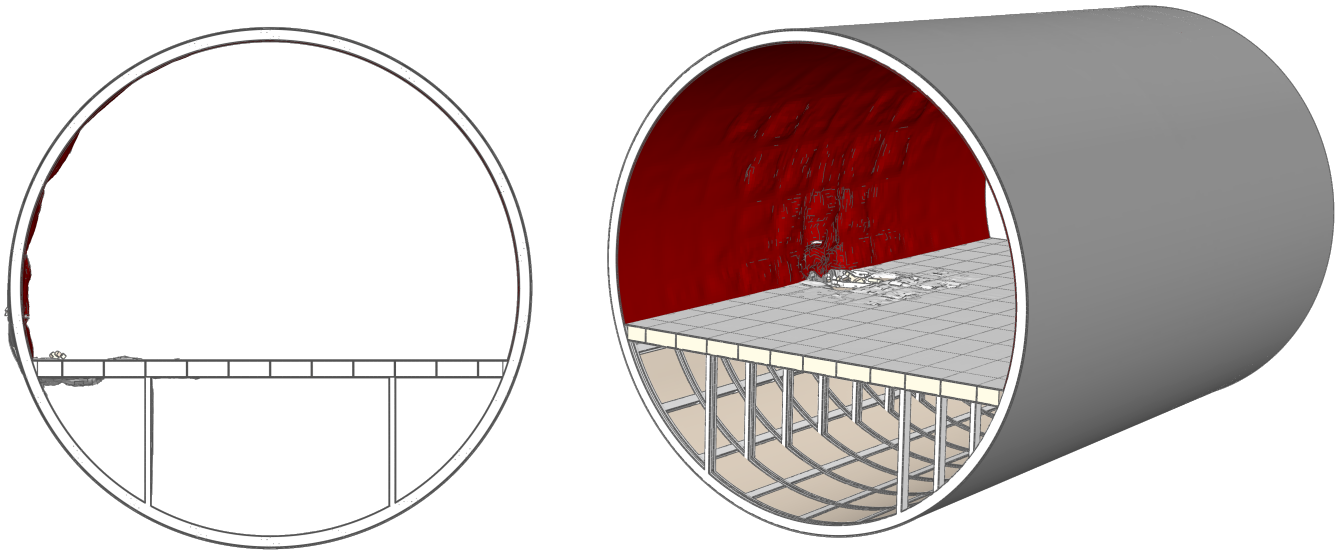

Figure 23: Structural damage at the end of the calculations, with CLD. 

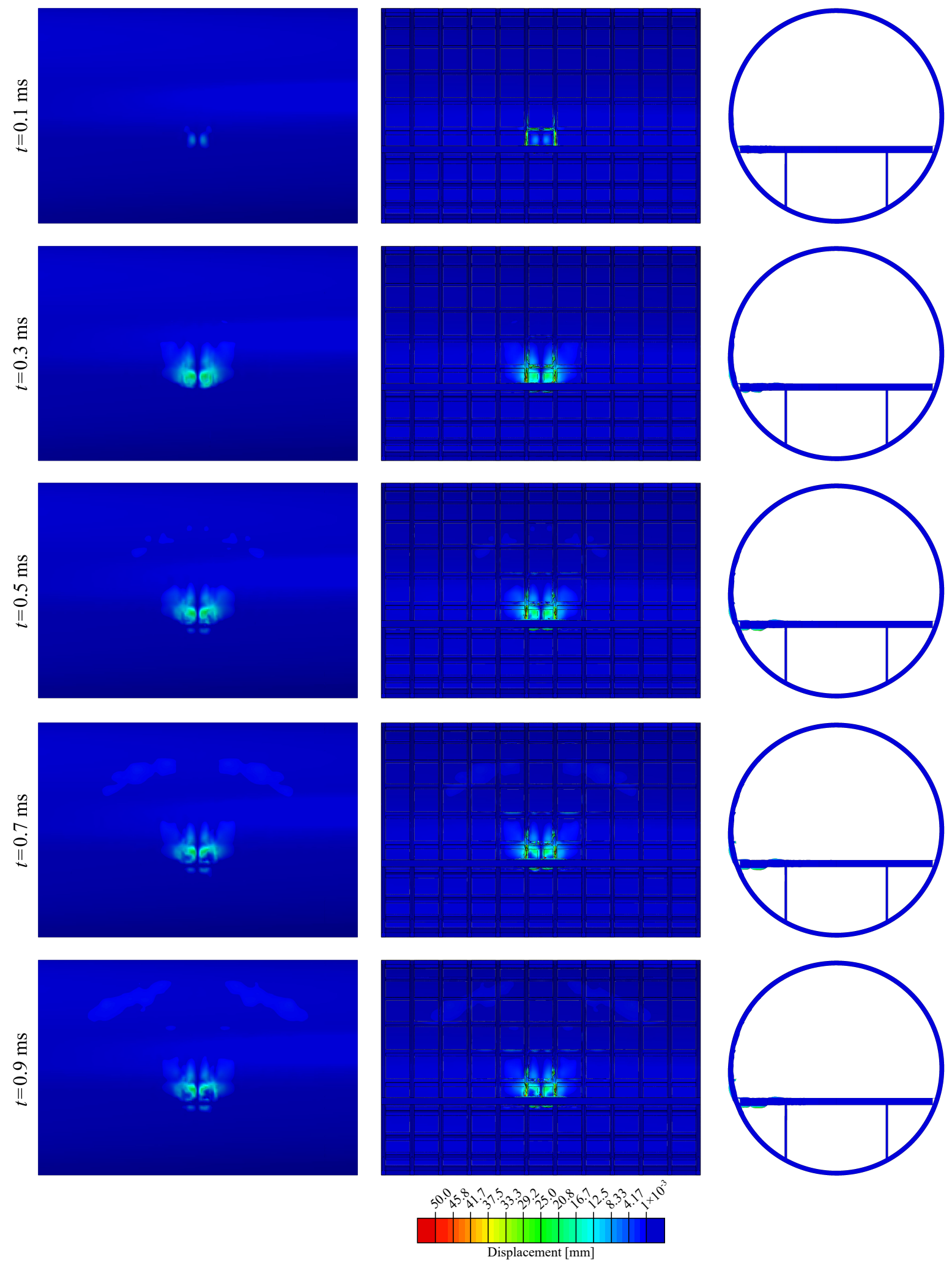

Figure 24: Simulation of an internal blast with CLD: external (left), internal (center), and front views (right). 


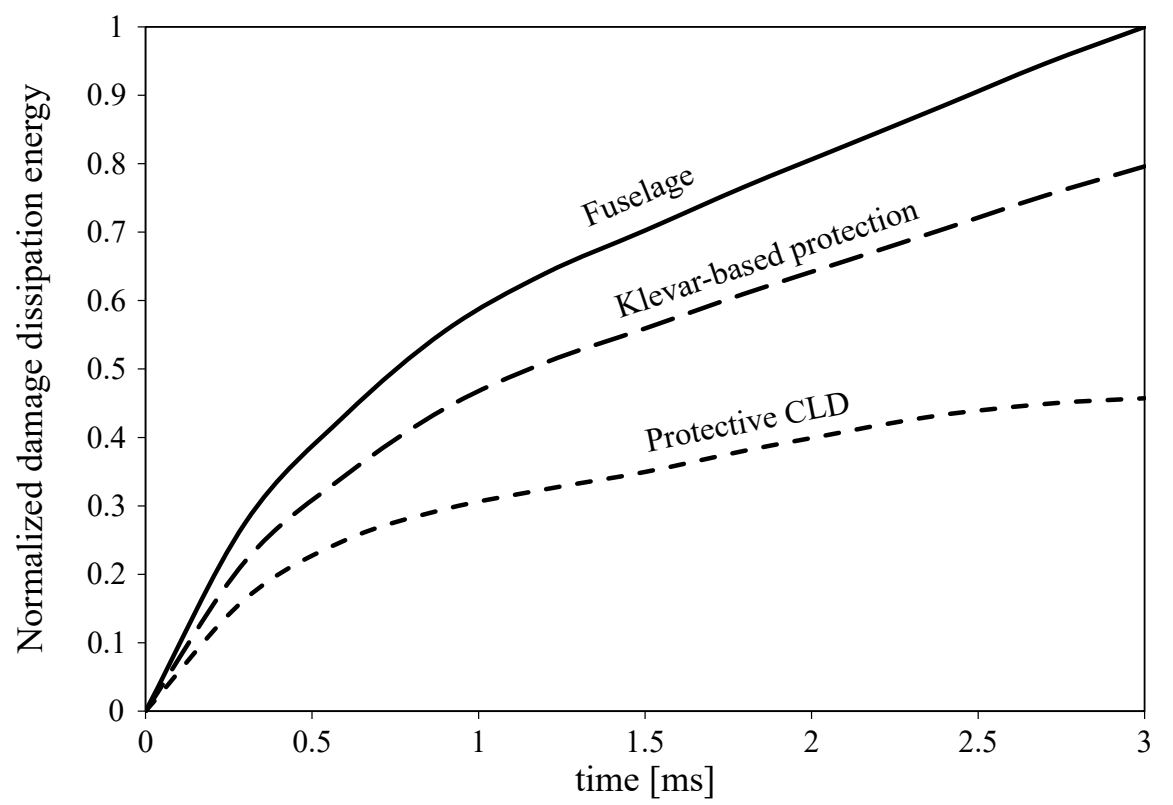

Figure 25: Evolution of the (normalized) energy dissipated through damage in the three cases: without protections, with Kevlar, and with the protective CLD. 
Table 1: Non-accidental explosions in airplanes, from 9].

\begin{tabular}{|c|c|c|c|}
\hline Date & Flight & Description & Casualities \\
\hline 1933 & Boeing 247D, United Air Lines & $\begin{array}{l}\text { bomb made of nytroglicerin } \\
\text { placed in the baggage compartment }\end{array}$ & 7 \\
\hline 1949 & $\begin{array}{l}\text { Douglas C-47-DL, } \\
\text { Canadian Pacific Airlines }\end{array}$ & $\begin{array}{l}\text { bomb made of dynamite } \\
\text { placed in the baggage compartment }\end{array}$ & 23 \\
\hline 1955 & Douglas DC-6B, United Air Lines & bomb made of dynamite & 44 \\
\hline 1962 & Boeing 707-124, Continental Air Lines & explosive device inside passenger cabin & 45 \\
\hline 1966 & Douglas RD4-1, Aden Airlines & explosive device inside passenger cabin & 30 \\
\hline 1967 & $\begin{array}{l}\text { DH-106 Comet } 4, \\
\text { British European Airways }\end{array}$ & $\begin{array}{l}\text { high explosive device } \\
\text { within the cabin under seats }\end{array}$ & 66 \\
\hline 1970 & $\begin{array}{l}\text { Convair CV-990-30A-6 Conorado, } \\
\text { Swissair }\end{array}$ & bomb in the baggage compartment & 47 \\
\hline 1976 & Douglas DC-8-43, Cubana de Aviación & explosive device at the rear of the cabin & 73 \\
\hline 1976 & Boeing 720-023B, Middle East Airlines & bomb in the baggage compartment & 81 \\
\hline 1982 & Boeing 747-121, Pan Am & bomb placed under a seat cushion & 1 \\
\hline 1985 & Boeing 747-237B, Air India & $\begin{array}{l}\text { high explosive device inside } \\
\text { the cargo compartment }\end{array}$ & 329 \\
\hline 1986 & Boeing 727-231, Trans World Airlines & explosive device in the cabin & 4 \\
\hline 1986 & Boeing 737-270C, Iraqi Airways & two hand grenades in the cabin & 63 \\
\hline 1987 & Boeing 707-3B5C, Korean Air & $\begin{array}{l}\text { liquid explosives concealed } \\
\text { as liquor bottles }\end{array}$ & 115 \\
\hline 1988 & Boeing 747-121, Pan Am & high-explosive device in the cabin & 270 \\
\hline 1989 & $\begin{array}{l}\text { McDonnel Douglas DC-10-30, } \\
\text { Union de Transport Aériens }\end{array}$ & $\begin{array}{l}\text { high explosive device } \\
\text { in the cargo hold }\end{array}$ & 170 \\
\hline 1989 & Boeing 727-21, Avianca Airlines & explosive near the fuel tank & 110 \\
\hline 2001 & Boeing 767, American Airlines & $\begin{array}{l}\text { plastic explosive concealed } \\
\text { within shoes }\end{array}$ & 0 \\
\hline 2004 & $\begin{array}{l}\text { Tupolev Tu-134-3, Volga-Avia Express } \\
\text { Tupolev Tu-154B-2, Siberia Airlines }\end{array}$ & $\begin{array}{l}\text { high explosive } \\
\text { devices }\end{array}$ & 90 \\
\hline 2015 & Airbus A32-231, Metrojet & $1 \mathrm{~kg}$ of $\mathrm{TNT}$ & 224 \\
\hline 2016 & Airbus A321-111, Daallo Airlines & $\begin{array}{l}\text { explosive device concealed within } \\
\text { a laptop computer }\end{array}$ & 1 \\
\hline
\end{tabular}


Table 2: Physical parameters for the state equations for air an explosive, after [21] and 22].

\begin{tabular}{ccccccccc}
\hline AIR & $\rho$ & Temperature & Gas constant & Specific heat & & & & \\
& {$\left[\mathrm{kg} / \mathrm{m}^{3}\right]$} & {$[\mathrm{K}]$} & {$[\mathrm{J} /(\mathrm{kg} \mathrm{K})]$} & {$[\mathrm{W} /(\mathrm{m} \mathrm{K})]$} & & & & \\
& 1.225 & 288.2 & 287.058 & 717.6 & & & & \\
\hline TNT & $\rho_{0}$ & $v_{D}$ & $A$ & $B$ & $\omega$ & $R_{1}$ & $R_{2}$ & $e_{0}$ \\
& {$\left[\mathrm{~kg} / \mathrm{m}^{3}\right]$} & {$[\mathrm{m} / \mathrm{s}]$} & {$[\mathrm{MPa}]$} & {$[\mathrm{MPa}]$} & & & & {$[\mathrm{kJ} / \mathrm{kg}]$} \\
& 1630 & 6930 & 373770 & 3747.1 & 0.35 & 4.15 & 0.9 & 3680
\end{tabular}

Table 3: Material elastic and thermal parameters.

\begin{tabular}{lccccc}
\hline Material & $\rho$ & $E$ & $\nu$ & $\begin{array}{c}\text { Specific } \\
\text { heat } \\
{[\mathrm{J} /(\mathrm{kg} \mathrm{K})]}\end{array}$ & $\begin{array}{c}\text { Thermal } \\
\text { conductivity } \\
{[\mathrm{W} /(\mathrm{m} \mathrm{K})]}\end{array}$ \\
\hline Al7075-T6 & 2810 & 71.7 & 0.33 & 848 & 130 \\
Al2024-T3 & 2770 & 73.1 & 0.33 & 863 & 121
\end{tabular}

Table 4: Material parameters for Johnson-Cook's plasticity (according to 34 and 35).

\begin{tabular}{lcccccccc}
\hline Material & $\begin{array}{c}J C_{1} \\
{[\mathrm{MPa}]}\end{array}$ & $\begin{array}{c}J C_{2} \\
{[\mathrm{MPa}]}\end{array}$ & $n$ & $m$ & $J C_{3}$ & $\begin{array}{c}T_{\mathrm{r}} \\
{[\mathrm{K}]}\end{array}$ & $\begin{array}{c}T_{\mathrm{m}} \\
{[\mathrm{K}]}\end{array}$ & $\begin{array}{c}\dot{\varepsilon}_{0} \\
{[1 / \mathrm{s}]}\end{array}$ \\
\hline Al7075-T6 & 517 & 405 & 0.41 & 1.1 & 0.0075 & 292.2 & 750 & 0.000161 \\
Al2024-T3 & 265 & 426 & 0.34 & 1.0 & 0.015 & 293.2 & 775 & 1.0
\end{tabular}

Table 5: Material parameters for Johnson-Cook's damage (according to [34 and 35]).

\begin{tabular}{lcccccc}
\hline Material & $d_{1}$ & $d_{2}$ & $d_{3}$ & $d_{4}$ & $d_{5}$ & $\begin{array}{c}\text { Elongation } \\
\text { at break } \\
{[\%]}\end{array}$ \\
\hline Al7075-T6 & 0.005 & 0.34 & -1.5 & -0.039 & 8 & 22 \\
Al2024-T3 & 0.13 & 0.13 & -1.5 & 0.011 & 0 & 18
\end{tabular}

Table 6: Material parameters for Kevlar fabric (according to [37] and [38]).

\begin{tabular}{ccccc}
\hline $\begin{array}{c}\rho \\
{\left[\mathrm{kg} / \mathrm{m}^{3}\right]}\end{array}$ & $\begin{array}{c}E_{1} \\
{[\mathrm{GPa}]}\end{array}$ & $\begin{array}{c}E_{2} \\
{[\mathrm{GPa}]}\end{array}$ & $\begin{array}{c}G_{12} \\
{[\mathrm{GPa}]}\end{array}$ & $\nu_{12}$ \\
\hline 1230 & 18.5 & 18.5 & 0.77 & 0.25
\end{tabular}

Table 7: Material parameters for Hashin's failure criterion [38.

\begin{tabular}{ccccccc}
\hline $\begin{array}{c}X^{t} \\
{[\mathrm{MPa}]}\end{array}$ & $\begin{array}{c}X^{c} \\
{[\mathrm{MPa}]}\end{array}$ & $\begin{array}{c}Y^{t} \\
{[\mathrm{MPa}]}\end{array}$ & $\begin{array}{c}Y^{c} \\
{[\mathrm{MPa}]}\end{array}$ & $\begin{array}{c}S^{t} \\
{[\mathrm{MPa}]}\end{array}$ & $\begin{array}{c}S^{l} \\
{[\mathrm{MPa}]}\end{array}$ & $\begin{array}{c}G_{f} \\
{\left[\mathrm{~kJ} / \mathrm{m}^{2}\right]}\end{array}$ \\
\hline 555 & 555 & 34.5 & 34.5 & 898 & 77 & 1.64
\end{tabular}


Table 8: Characteristics of the studied structural meshes.

\begin{tabular}{lrrr}
\hline Mesh & Average element size $[\mathrm{mm}]$ & Number of elements & Number of DOF $[\mathrm{mln}]$ \\
\hline $\mathrm{MS}_{1}$ & 10 & 9191 & $7.23 \times 10^{-2}$ \\
$\mathrm{MS}_{2}$ & 8 & 12520 & $1.01 \times 10^{-1}$ \\
$\mathrm{MS}_{3}$ & 6 & 21329 & $1.73 \times 10^{-1}$ \\
$\mathrm{MS}_{4}$ & 5 & 27971 & $2.24 \times 10^{-1}$ \\
$\mathrm{MS}_{5}$ & 4 & 40813 & $3.22 \times 10^{-1}$ \\
$\mathrm{MS}_{6}$ & 3 & 74611 & $5.87 \times 10^{-1}$ \\
$\mathrm{MS}_{7}$ & 2 & 159764 & 1.26 \\
$\mathrm{MS}_{8}$ & 1.5 & 266811 & 2.10 \\
$\mathrm{MS}_{9}$ & 1 & 597159 & 4.7
\end{tabular}




\section{Appendix}

We analyze here the numerical procedure used in the above numerical simulations and presented in Section 6. We pay attention to the use of two distinct volumes of air to represent the pressurization load in terms of a pressure gradient. We aim at a reasonable characterization of the pressure evolution on the cabin, which may be decompressed, due to the explosion-induced damage. Hence, we simulate a sudden loss of internal pressure.

We proceed as follows: First, we compute the stress distribution in the fuselage, by applying gravity, lift, and pressurization loads, along the path described in Section 6. Then, we impose a $100 \times 100 \mathrm{~mm}$ square hole over the skin by equating to zero the strength of the corresponding finite elements (see Fig. 26).

The air flows outside the hole, due to the pressure gradient, at high velocity. The material around the hole undergoes plastic strain; damage increases. Figure 27 shows the evolution of the pressure field immediately after the puncturing, while the structural response is displayed in Figure 28.

The simulations do not describe the whole decompression event; calculations end, in fact, after $30 \mathrm{~ms}$ (see Fig. 29). In any case, however, the numerical results show that the procedure of defining two distinct volumes of air can take into account the abrupt changes in the pressure field (thus in the pressurization load). At variance, we would neglect a physically significant physical contribution (abrupt pressure variation).

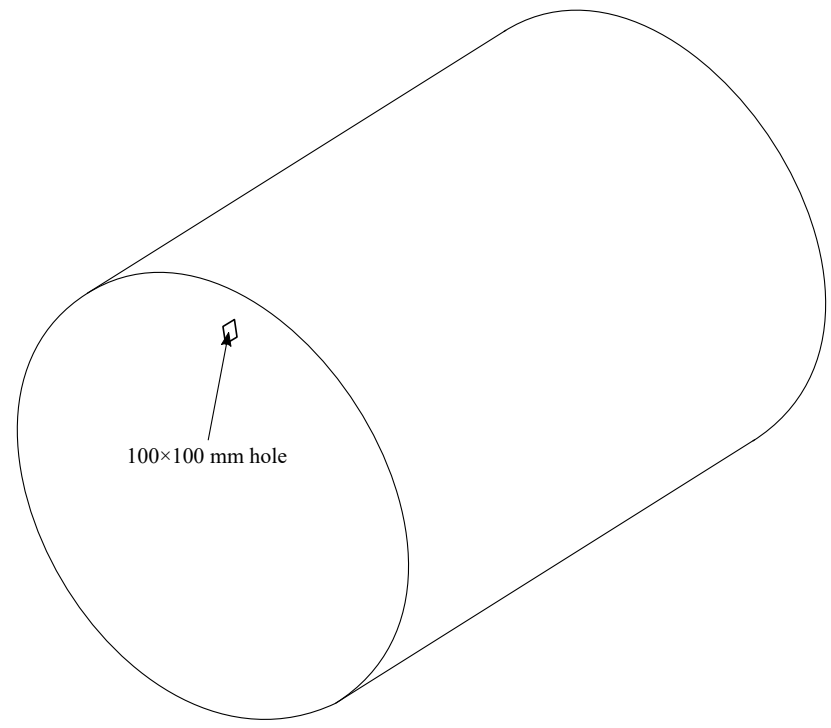

Figure 26: Location of the square hole with zero strength. 

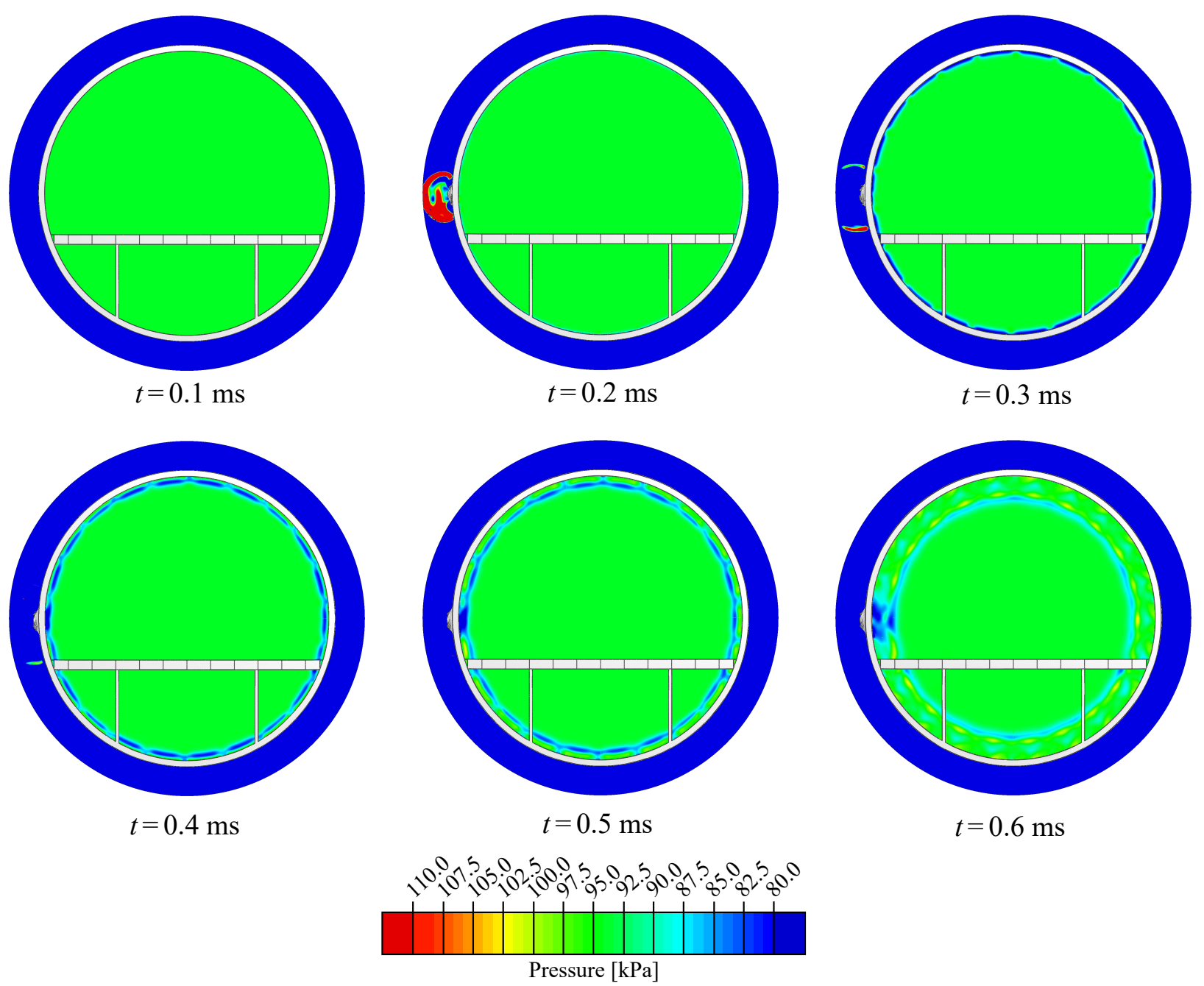

Figure 27: Evolution of the pressure field after the removal of a $100 \times 100$ square hole from the skin. 

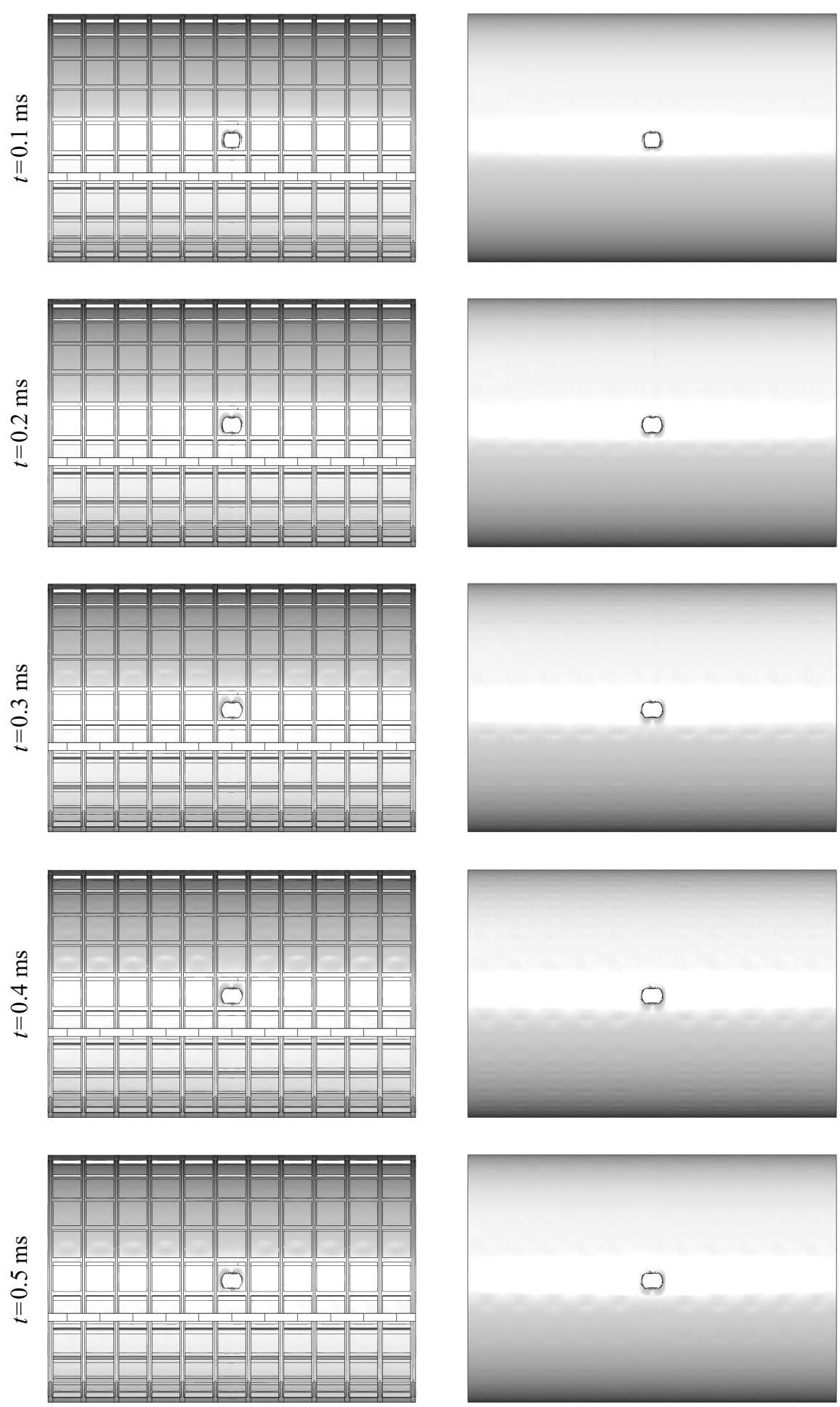

Figure 28: Structural response after the removal of a $100 \times 100$ square hole from the skin. 

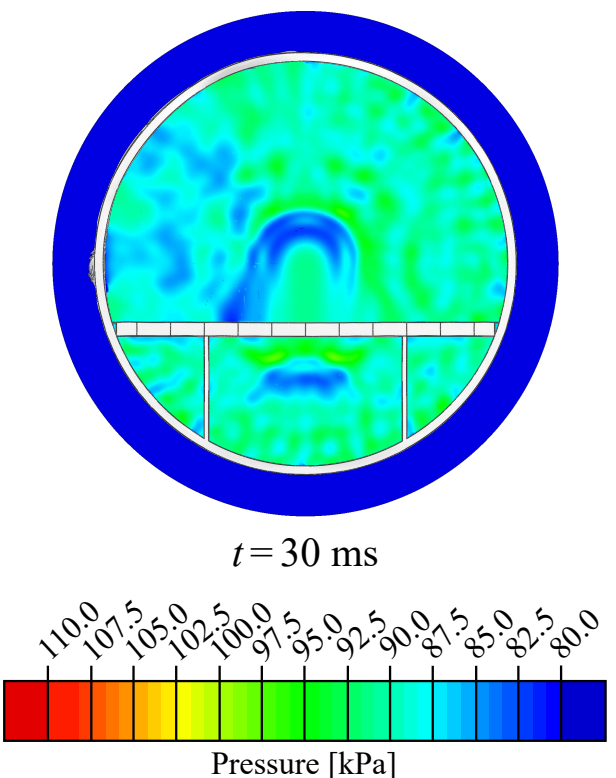

Figure 29: Pressure field at the end of the calculations. 
[1] Gillen, D. and Morrison, W. G., "Aviation security: Costing, pricing, finance and performance," Journal of Air Transport Management, Vol. 48, 2015, pp. 1-12. doi: 10.1016/j.jairtraman.2014.12.005

[2] Mlakar, P. F. and Klein, H. H. and Smith, J. L., "Hardened Unit Load Devices," Proceedings FAA Aircraft Hardening and Survivability Symposium, 1992, pp. 1-7.

[3] Sanai, M. and Greenfield, G. R., "Hardened Luggage Container," United States Patent US 5,267,665, 1993.

[4] Fray, J., "Venting a space to relieve pressure generated by an explosion," British Aerospace Public Limited Company $07 / 897,495,1992$.

[5] Hararat-Tehrani, M., "Decompression panel for a separation device in an aircraft," Deutsche Airbus Gmbh 07/626,888, 1992.

[6] Settles, G. S. and Keane, B.T and Anderson, B. W. and Gatto, J. A., "Shock waves in aviation security and safety," Shock Waves, Vol. 12, No. 4, 2003, pp. 267-275. doi. 10.1007/s00193-002-0162-1

[7] Backman, D. and Gould, R., "Blast Response of a Pressurized Aircraft Fuselage Measured Using High-Speed Image Correlation," Experimental Techniques, Vol. 39, 2015, pp. 4-9. doi: 10.1111/ext.12001

[8] Veldam, R. L. and Ari-Gur, J. and Clum, C., "Response of pre-pressurized reinforced plates under blast loading," International Journal of Impact Engineering, Vol. 35, No. 4, 2008, pp. 240-250. doi: 10.1016/j.ijimpeng.2007.01.006

[9] Flight Safety Foundation, Aviation safety database, 2017, url: https://aviation-safety.net/

290 [10] Soutis, C. and Mohamed, G. and Hodzic, A., "Modelling the structural response of GLARE panels to blast load," Composite Structures, Vol. 94, No. 1, 2011, pp. 267-276. doi: 10.1016/j.compstruct.2011.06.014

[11] Dacko, A. and Toczyski, J., "Vulnerability analysis of aircraft fuselage subjected to internal explosion," The Arhive of Mechanical Engineering, Vol. 58, No. 4, 2011. doi: 10.2478/v10180-011-0024-4

[12] Kotzakolios, T. and Vlachos, D. E. and Kostopoulos, V., "Blast response of metal composite laminate fuselage structures using finite element modelling," Composite Structures, Vol. 93, No. 2, 2011, pp. 665-681. doi: $10.1016 /$ j.compstruct.2010.08.012

[13] Dewey, J. M., "Measurement of the physical properties of blast waves," In: Experimental methods of shock wave research, Springer, Cham, 2016, pp. 53-86. doi: 10.1007/978-3-319-23745-9-2

[14] Sochet, I. ed., Blast effects. Physical properties of shock waves, In: Shock Wave and High Pressure Phenomena, Springer, Cham, 2018. doi: 10.1007/978-3-319-70831-7

[15] Needham, C. E., Blast waves, 2nd ed., In: Shock Wave and High Pressure Phenomena, Springer, Berlin, Heidelberg, 2018. doi: $10.1007 / 978-3-642-05288-0$

[16] Remennikov, A.M., "A review of methods for predicting bomb effects on buildings", Journal of Battlefield Technology, Vol. 6, No. 3, 2003, pp. 5-10.

[17] Larcher, M., "Simulation of the effects of an air blast wave," JRC European Commission, JRC 41337, Luxembourg, 2007.

[18] Jones, H. and Miller, A. R., "The detonation of solid explosives: the equilibrium conditions in the detonation wave-front and the adiabatic expansion of the products of detonation," Proc. Royal Soc. A, Vol. 194, No. 1039, 1948, pp. 480. doi: 10.1098/rspa.1948.0093

[19] Wilkins, M. L., "The equation of state of PBX 9404 and LX 04-01," Lawrence Radiation Laboratory, TID 4500 - UCRL 50422, Livermore, 1968.

[20] Lee, E. L. and Horning, H. C. and Kury, J. W., "Adiabatic expansion of high explosives detonation products," Lawrence Livermore National Laboratory, UCRL - 7797, Livermore, 1964.

[21] Rogers, G.F.C. and Mayhew, Y.R., Thermodynamic and Transport Properties of Fluids, Wiley, 1988.

[22] Lee, E. and Finger, M. and Collins, W., "JWL equation of state coefficient for high explosives," Lawrence Livermore National Laboratory, UCID - 16189, Livermore, 1973.

[23] Boyer, D. W., "An experimental study of the explosion generated by a pressurized sphere," Journal of Fluid Mechanics, Vol. 9, No. 3, 1960, pp. 401-429. doi: 10.1017/S0022112060001195

[24] USACE, "Design and Analysis of Hardened Structures to Conventional Weapons Effects," U. S. Army, TM 5-855-1, 1986.

[25] USACE, "Structures to Resist the Effects of Accidental Explosions," U. S. Army, TM 5-1300, 1990.

320 [26] USACE, "Structures to Resist the Effects of Accidental Explosions," U. S. Army, UFC 3-340-02, 2008

[27] Karlos, V. and Solomos, G., "Calculation of Blast Loads for Application to Structural Components," Joint Research Center of the European Commission, JRC 32253-2011, 2013.

[28] Kingery, C. N. and Bulmash, G., "Air blast parameters from TNT spherical air burst and hemispherical burst," U.S. Army Ballistic Research Laboratory, ARBRL-TR-02555, 1984.

[29] Vannucci, P. and Stefanou, I. and Masi, F., "Cathédrales durables," CNRS, Final report, Paris, 2017.

[30] Vannucci, P. and Masi, F. and Stefanou, I., "A study on the simulation of blast actions on a monumental structure," 2017. url: https://hal.archives-ouvertes.fr/hal-01720557/

[31] Masi, F., "Blast actions from high explosives. Studies on their simulation and effects", Master Thesis, University of Florence, 2017. doi: 10.17605/osf.io/ekus8

[32] Masi, F. and Stefanou, I. and Vannucci, P., "A study on the effects of an explosion in the Pantheon of Rome," Engineering Structures, Vol. 164, 2018, pp. 259-273. doi: 10.1016/j.engstruct.2018.02.082

[33] Johnson, G. and Cook, W. H., "A constitutive model and data for metals subjected to large strains, high strain rates and high temperatures," Proceedings of the 7th International Symposium on Ballistics, Vol. 21, The Hague, 1983, pp. 541-547.

[34] Corona, E. and Orient, G. E., "An Evaluation of the Johnson-Cook Model to Simulate Puncture of 7075 Aluminum Plates," Sandia National Laboratories, SAND2014-1550 505013, Albuquerque, 2014.

[35] Kray, G., "Failure modeling of titanium 6Al-4V and aluminum 2024-T3 woth the Johnson-Cook material model," Lawrence Livermore National Lab., UCRL-ID-149880, Livermore, 2002.

[36] ABAQUS (2016), "ABAQUS Documentation", Dassault Systèmes, Paris, FR. 
[37] Zhu, G. and Glodsmith, W. and Dharan, C. K. H., "Penetration of laminated Kevlar by projectiles - I. Experimental investigation," International Journal of Solids Structures, Vol. 29, No. 4, 1992, pp. 399-420. doi: 10.1016/0020-7683(92)90207-A

[38] Cheeseman, B. A. and Bogetti, B. A., "Ballistic impact into fabric and compliant composite laminates," Composite Structures, Vol. 61, No. 1-2, 2003, pp. 161-173. doi: 10.1016/S0263-8223(03)00029-1

[39] Hashin, Z., "Failure Criteria for Unidirectional Fiber Composites," Journal of Applied Mechanics, Vol. 47, No. 2, 1980, pp. 329-334. doi: 10.1115/1.3153664

[40] Wang, Y. and Li, J. and Zhao, D., 'Mechanical properties of fiber glass and Kevlar woven fabric reinforced composites',' Composites Engineering, Vol. 5, No. 9, 1995, pp. 1159-1175. doi: 10.1016/0961-9526(95)00100-2

[41] Goods, S. H. and Neuschwanger, C. L. and Henderson, C. and Skala, D. M., "Mechanical properties and energy absorption characteristics of a polyurethane foam", Sandia National Laboratories, SAND97-8490 UC 404, Albuquerque and Livermore, 1997.

[42] Sachs, R. G., "The dependence of blast on ambient pressure and temperature", Technical report, Army Ballistic Research Lab 466, 1944.

[43] Rediess, H., "Aircraft blast mitigation", talk at ST Stakeholders Conference, June 2-5, 2008 (see https://ndiastorage.blob.core.usgovcloudapi.net/ndia/2008/homest/blast.pdf).

[44] Civil Aviation Authority, London, "Aircraft Hardening Research Programme Final Overview Report", ISBN 086039828 5 (see https://publicapps.caa.co.uk/docs/33/CAPAP200109.PDF) 